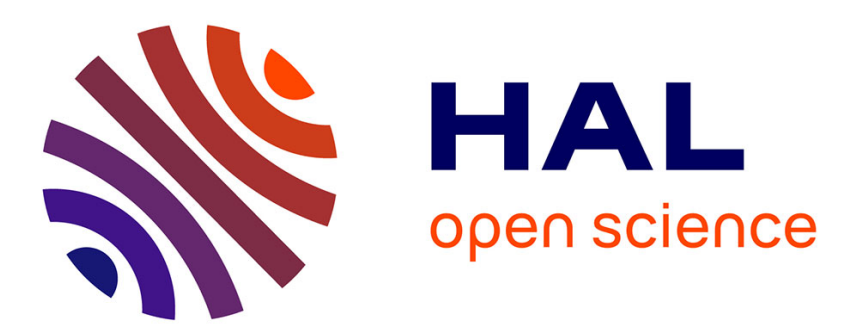

\title{
De vastes propriétés au cour des villes: le patrimoine urbain des communautés régulières à Bordeaux au milieu du XVIIIe siècle
}

Aude Loriaud

\section{- To cite this version:}

Aude Loriaud. De vastes propriétés au cœur des villes: le patrimoine urbain des communautés régulières à Bordeaux au milieu du XVIIIe siècle. Histoire, économie et société, 2019, 2, pp.23-46. 10.3917/hes.192.0023 . halshs-03207413

\section{HAL Id: halshs-03207413 \\ https://shs.hal.science/halshs-03207413}

Submitted on 1 May 2021

HAL is a multi-disciplinary open access archive for the deposit and dissemination of scientific research documents, whether they are published or not. The documents may come from teaching and research institutions in France or abroad, or from public or private research centers.
L'archive ouverte pluridisciplinaire HAL, est destinée au dépôt et à la diffusion de documents scientifiques de niveau recherche, publiés ou non, émanant des établissements d'enseignement et de recherche français ou étrangers, des laboratoires publics ou privés. 
Pour citer cet article : LORIAUD Aude, « De vastes propriétés au cour des villes : le patrimoine urbain des communautés régulières à Bordeaux au milieu du XVIII ${ }^{\mathrm{e}}$ siècle ", Histoire, économie \& société, $\mathrm{n}^{\circ} 2 / 2019$ : L'emprise foncière des religieux dans l'espace urbain sous l'Ancien Régime, juin 2019, p. 23-46.

\title{
DE VASTES PROPRIÉTÉS AU CCEUR DES VILLES : LE PATRIMOINE URBAIN DES COMMUNAUTÉS RÉGULIÈRES À BORDEAUX AU MILIEU DU XVIII' SIÈCLE
}

\author{
par Aude LORIAUD
}

Résumé

Peut-on estimer l'emprise foncière des religieux dans l'espace urbain bordelais au milieu du $X V I I I^{e}$ siècle? Bordeaux faisait partie des cinq villes les plus peuplées du royaume de France et abritait une trentaine de communautés régulières. L'étude de la répartition des couvents et de leurs logiques d'implantation met en évidence une domination symbolique des réguliers dans le paysage. Leur présence dans le tissu urbain se traduisait en outre par des biens locatifs dont il est intéressant d'analyser les caractéristiques et la dispersion, en cherchant des critères de différenciation tels que l'ancienneté des communautés, leur taille, leur nature (ordres ou congrégations) ou leur genre. Enfin, pour confirmer ou relativiser l'emprise spatiale des réguliers, il faut pouvoir la comparer aux autres propriétaires ecclésiastiques.

\section{Abstract}

Is there a land influence of religious communities in the urban space of Bordeaux in the middle of the $18^{\text {th }}$ century? There were about thirty regular communities in Bordeaux, one of the five most populous cities in France. The study of convents' distribution and setting up logics highlights their symbolic domination in the urban fabric. The analysis of their rental properties' characteristics and their dispersal shows another form of religious communities' land influence. To compare communities, it is interesting to look for criteria of differentiation like long-standing, size, kind (orders or congregations) or gender. Finally, the regular communities' spatial influence must be compared with others holders of the Catholic Church's land properties, to confirm or relativize this domination.

La ville de Bordeaux fut profondément transformée par les nombreuses fondations de la 
Pour citer cet article : LORIAUD Aude, « De vastes propriétés au cour des villes : le patrimoine urbain des communautés régulières à Bordeaux au milieu du XVIII ${ }^{\mathrm{e}}$ siècle ", Histoire, économie \& société, $\mathrm{n}^{\circ} 2 / 2019$ : L'emprise foncière des religieux dans l'espace urbain sous l'Ancien Régime, juin 2019, p. 23-46.

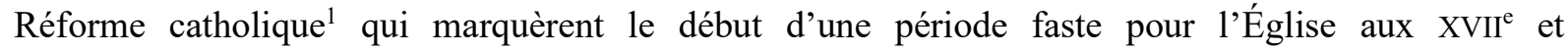
$\mathrm{XVIII}^{\mathrm{e}}$ siècles${ }^{2}$. Vers 1750 , elle faisait partie des cinq villes les plus peuplées du royaume de France, avec 60000 habitants, et abritait une trentaine de communautés régulières. Chaque fondation de communauté religieuse se concrétisa par l'achat d'un emplacement, des acquisitions progressives tout autour afin de regrouper plusieurs bâtisses, les réaménager ou les détruire afin de bâtir un grand monastère ${ }^{3}$. Une fois bien implantées, les communautés religieuses continuèrent très souvent à étendre leurs propriétés aux abords des couvents, non pas pour inclure ces nouveaux immeubles dans l'enclos régulier, mais pour en tirer des revenus locatifs. Or, le corps de ville percevait ce processus comme un accroissement des biens de mainmorte dommageable à l'économie de la cité. Cependant, quelle était véritablement la part de l'occupation spatiale des religieux dans la cité bordelaise au milieu du XVIII ${ }^{\mathrm{e}}$ siècle ? Peut-on mesurer cette emprise foncière et la comparer au clergé séculier ou à d'autres groupes?

Outre les sources incontournables sur les établissements monastiques dans les séries $\mathrm{G}$ et $\mathrm{H}$ des archives départementales de la Gironde que nous avons exploitées dans notre thèse, deux sources essentielles peuvent permettre de répondre à cette question : un dénombrement des maisons de Bordeaux vers $1750^{4}$ et le plan de la ville et faubourgs en 1760, gravé par Lattré ${ }^{5}$. Cette période est propice à l'observation d'un patrimoine ecclésiastique assez stable. En effet, aucune maison religieuse ne fut fermée à Bordeaux, ni par la Commission des Secours, ni par la Commission des Réguliers ; et les Jésuites, qui faisaient partie des plus gros propriétaires fonciers, n'avaient pas encore été supprimés ${ }^{6}$.

L'étude de la place des religieux dans l'espace urbain sera présentée en deux temps: premièrement, à travers la forme la plus visible de leur présence, c'est-à-dire leurs enclos conventuels ; ensuite, à travers leurs possessions immobilières plus discrètes, à savoir leurs biens locatifs.

\footnotetext{
${ }^{1}$ Bernard Peyrous, La Réforme catholique à Bordeaux (1600-1719) : le Renouveau d'un diocèse, Bordeaux, FHSO, 1995, 2 vol.

${ }^{2}$ Philippe Loupès, L'Apogée du catholicisme bordelais (1600-1789), Bordeaux, Mollat, 2001.

${ }^{3}$ Sur les différents processus de constitution des enclos conventuels féminins à Bordeaux et à Rouen, voir : Aude Loriaud, Les Clefs du cloître. Les Communautés religieuses féminines à Bordeaux et à Rouen aux XVII et $X V I I I^{e}$ siècles, thèse de doctorat d'histoire sous la direction de M. Éric Suire à l'Université Bordeaux Montaigne, en préparation depuis 2016. Sur ce sujet, se référer à : Dominique Dinet, Religion et société : les Réguliers et la vie régionale dans les diocèses d'Auxerre, Langres et Dijon (fin XVI - fin XVIII' siècles), Paris, Publications de la Sorbonne, 1999, 2 vol.; Laurent Lecomte, Religieuses dans la ville. L'architecture des Visitandines (XVII ${ }^{\text {- }}$ XVIII siècles), Éditions du Patrimoine, 2013.

${ }^{4}$ Archives départementales de la Gironde [désormais AD Gironde], C 1276, Dénombrement des propriétaires et locataires des maisons et échoppes de la ville de Bordeaux par régiment (vers 1750-1752).

${ }^{5}$ Archives Nationales [désormais AN], N/III/Gironde/33/2, « Plan de la ville et faubourgs de Bordeaux, à Paris, chez Lattré graveur, rue Saint-Jacques au coin de celle de la Parcheminerie, à la ville de Bordeaux avec privilège du Roy, $1760 »$.

${ }^{6}$ L'arrêt du Parlement de Guyenne qui proclama la dissolution de la Compagnie de Jésus intervint le 26 mai 1762. Éric Suire, "La proscription du "jésuitisme" à Bordeaux au XVIII" siècle », dans François Cadilhon, Philippe Chassaigne, Éric Suire (dir.), Censure et autorités publiques de l'époque moderne à nos jours, Bruxelles, P.I.E. Peter Lang, 2015, p. 161-176, ici p. 166.
} 
Pour citer cet article : LORIAUD Aude, « De vastes propriétés au cour des villes : le patrimoine urbain des communautés régulières à Bordeaux au milieu du XVIII ${ }^{\mathrm{e}}$ siècle ", Histoire, économie \& société, $\mathrm{n}^{\circ} 2 / 2019$ : L'emprise foncière des religieux dans l'espace urbain sous l'Ancien Régime, juin 2019, p. 23-46.

\section{Les établissements monastiques dans l'espace urbain bordelais}

On peut d'abord prendre la mesure de l'occupation matérielle de l'espace urbain par les religieux à travers la forme la plus évidente de leur présence : les établissements monastiques. Comme d'autres villes où la Réforme catholique a rayonné, Bordeaux n'a pas échappé à un phénomène d'invasion conventuelle ${ }^{7}$ - comme Rouen ${ }^{8}$, Lille $^{9}$, Naples ${ }^{10}$ ou Séville ${ }^{11}$, pour ne citer que quelques exemples puisque le nombre de communautés régulières a triplé à Bordeaux entre le début du XVII ${ }^{\mathrm{e}}$ siècle et la fin du XVIII ${ }^{\mathrm{e}}$ siècle, passant de neuf à trente (fig. 1) 12. $^{12}$.

\section{La répartition des monastères et des couvents}

À l'échelle de la cité bordelaise, la densité de monastères était importante dans le quart sudouest de la cité. La paroisse Sainte-Eulalie ${ }^{13}$ connut un processus de conventualisation à l'époque de la Réforme catholique, ce qui accentua la présence des religieux au sud de la ville, déjà forte depuis le XIII ${ }^{\mathrm{e}}$ siècle - à savoir les Carmes, les Augustins, les Cordeliers de l'Observance, sans compter les Clarisses qui s'éteignirent à la fin du XVI $I^{\mathrm{e}}$ siècle. Ce phénomène de conventualisation fut spécifiquement féminin car, sur les dix fondations régulières du XVII ${ }^{\mathrm{e}}$ siècle dans la paroisse Sainte-Eulalie, six concernaient des couvents de femmes. À l'inverse, on remarque une très faible densité d'établissements religieux dans le périmètre de la première enceinte, datant de 270 de notre ère, et même de la deuxième édifiée entre 1205 et 1225 (fig. 1) ${ }^{14}$. La présence de zones marécageuses empêchait, de manière générale,

\footnotetext{
${ }^{7}$ Notion élaborée par Alain Lottin dans sa thèse de doctorat Lille, citadelle de la Contre-Réforme? (1598-1668), Lille, Presses Universitaires du Septentrion, 2013, p. 159.

${ }^{8}$ Voir Bernard Gauthiez, La Logique de l'espace urbain, formation et évolution : le cas de Rouen, thèse de doctorat d'histoire sous la direction de Jean-Pierre Bardet, EHESS, 1991.

${ }^{9}$ Voir A. Lottin, Lille, citadelle de la Contre-Réforme?, op. cit.

${ }^{10}$ Voir Brigitte Marin, «Espaces sacrés, concessions de terrains publics et arrangements urbains à Naples au XVIII ${ }^{\mathrm{e}}$ siècle », dans Bruno Dumons, Bernard Hours (dir.), Ville et Religion en Europe du XVI au XX siècle, Grenoble, Presses Universitaires de Grenoble, 2010, p. 17-31.

${ }^{11}$ On trouvera de nombreux exemples, dont Séville, dans Dominique Dinet, « Abbayes, couvents et monastères dans l'espace urbain des cités de l'Europe moderne » dans Les Passions d'un historien. Mélanges en l'honneur de Jean-Pierre Poussou, Paris, Presses de l'Université de Paris-Sorbonne, 2010, p. 1461-1472, ici p. 1463. Le même auteur a développé les exemples de Dijon, Langres et Auxerre dans Religion et société, op. cit., t. 1, p. 255-273.

${ }^{12}$ Sur la figure 1, seules 27 communautés régulières sont représentées car les fonctions des Lazaristes, des Frères des Écoles Chrétiennes et des Filles de la Charité supposaient une présence diffuse dans l'agglomération. Les Jésuites détenaient trois établissements : le collège de la Madeleine, la maison-mère et le noviciat.

${ }^{13}$ Voir la figure 3 sur lequel les limites du régiment Sainte-Eulalie recoupent celles de la paroisse du même nom ; ce qui n'est pas le cas des autres régiments ou paroisses. On trouvera une carte des paroisses bordelaises sous l'Ancien Régime dans Ph. Loupès, L'Apogée du catholicisme bordelais, op. cit., p. 102. Voir aussi Marie Andrieu, Les paroisses et la vie religieuse à Bordeaux de 1760 à 1789, Thèse de $3^{\circ}$ cycle sous la direction de Philippe Loupès, Université Bordeaux III, 1973.

${ }^{14}$ Le tracé des remparts sur la figure 1 reprend le plan historique de Bordeaux vers 1550 par Ézéchiel Jean-Courret publié dans Sandrine Lavaud, Ézéchiel Jean-Courret (dir.), Bordeaux (Atlas historique), t. 2, Notice générale. La formation de l'espace urbain des origines à nos jours, Bordeaux, Ausonius, 2009, p. 150.
} 
Pour citer cet article : LORIAUD Aude, « De vastes propriétés au cour des villes : le patrimoine urbain des communautés régulières à Bordeaux au milieu du XVIII ${ }^{\mathrm{e}}$ siècle ", Histoire, économie \& société, $\mathrm{n}^{\circ} 2 / 2019$ : L'emprise foncière des religieux dans l'espace urbain sous l'Ancien Régime, juin 2019, p. 23-46.

le développement de la propriété conventuelle à la périphérie de la ville ${ }^{15}$. Les fondations hors les murs furent donc rares et éloignées les unes des autres. Les Chartreux de Vauclaire en Périgord trouvèrent refuge, en pleine guerre de Cent Ans, dans les marais au nord de Bordeaux, entre 1381 et $1446^{16}$. D'autres Chartreux s'établirent dès 1609 au milieu des marécages à l'ouest de la ville. Les Dominicaines de Sainte-Catherine se déplacèrent dans le faubourg Saint-Seurin en 1664. Enfin, les Carmes déchaux firent construire un second couvent, en 1673, dans le faubourg des Chartrons entre le fleuve et les marais.

\section{Les logiques d'implantation}

Quelles logiques présidèrent à l'implantation des religieux à l'époque moderne ? Sont-elles comparables aux logiques médiévales? Au XIII ${ }^{\mathrm{e}}$ siècle, moment fort dans l'histoire des fondations religieuses, les cinq couvents d'ordres mendiants qui s'établirent à Bordeaux choisirent les entrées de la ville $^{17}$. Quatre se situaient ainsi au sud de la ville, à proximité des grandes voies : les Carmes, les Augustins, les Cordeliers de l'Observance et les Clarisses. Un seul était localisé au nord : le monastère des Dominicains ${ }^{18}$. L'éphémère communauté des Frères de la Pénitence du Christ - ou Frères Sachets constitue une exception car elle s'installa à l'intérieur de l'ancienne enceinte, rue Porte-Dijeaux ${ }^{19}$. Le choix de se placer en dehors de la cité fortifiée s'explique d'abord par le caractère très dense et très morcelé du bâti de la ville médiévale, impropre à la construction de vastes monastères. En outre, l'accaparement des portes d'entrée de la ville est à mettre en lien avec leur mission de prédication ${ }^{20}$. Il faut aussi souligner l'obligation d'éloignement par rapport aux églises paroissiales, conformément aux normes fixées par le pape Clément IV en 1268 pour atténuer la concurrence dans l'administration des sacrements entre le clergé séculier et les ordres mendiants, dont les prêches remportaient un grand succès ${ }^{21}$.

En revanche, au siècle de la Réforme catholique, période de fondations religieuses sans précédent au sein des villes, ce ne sont plus les mêmes facteurs qui déterminent l'implantation des

\footnotetext{
${ }^{15}$ Jean-Pierre Poussou, « Bordeaux ou la ville sur les marais », Revue du Nord, hors-série n²6, 2011, p. 205-218.

${ }^{16}$ Bernard Peyrous, La Réforme catholique à Bordeaux, op. cit., t. 1, p. 362. Ils laissèrent leur nom au faubourg situé au nord de Bordeaux (les Chartrons).

${ }^{17}$ Sandrine Lavaud, Olivier Pissoat et al., «Étude chrono-chorématique : Bordeaux», M@ppemonde, n 114 (2014/2). URL : http://mappemonde-archive.mgm.fr/num42/articles/art14204.html

${ }^{18}$ Bernard Guillemain (dir.), Le Diocèse de Bordeaux, une histoire religieuse de la Gironde des origines à nos jours, Paris, Beauchesne, 1974.

${ }^{19}$ Léo Drouyn, Bordeaux vers 1450. Description topographique [1874], Livre II, Monein, Éd. Pyrémonde - Princi Negue, 2010, p. 76.

${ }^{20}$ Paul Christophe parle de « quadrillage de tout l'espace urbain » au sujet de l'implantation des ordres mendiants dans les grandes villes au XIII ${ }^{\mathrm{e}}$ siècle, dans le but de rendre leurs prédications plus efficaces. Paul Christophe, 2000 ans d'Histoire de l'Église, Paris, Mame-Desclée, 2012, p. 426. Mais le cas bordelais ne se prête pas à une telle qualification.

${ }^{21}$ Ibid., p. 426 et 428.
} 
Pour citer cet article : LORIAUD Aude, « De vastes propriétés au cour des villes : le patrimoine urbain des communautés régulières à Bordeaux au milieu du XVIII ${ }^{\mathrm{e}}$ siècle ", Histoire, économie \& société, $\mathrm{n}^{\circ} 2 / 2019$ : L'emprise foncière des religieux dans l'espace urbain sous l'Ancien Régime, juin 2019, p. 23-46.

religieux. Seul perdure l'évitement de la ville médiévale, dont le parcellaire était trop dense et morcelé22, à moins de réinvestir d'anciens bâtiments religieux, à l'instar des Feuillants ayant pris place dans l'ancien hôpital des Antonins. Avant tout, le choix d'un emplacement dépendait de la disponibilité des terrains en ville et de leur moindre prix, au regard des capacités financières de chaque communauté religieuse et des dons reçus pour son installation. Laurent Lecomte a exposé les critères de sélection des emplacements des Visitandines - l'espace, le bon air, le silence, l'isolement et la belle vue ${ }^{23}$ - tout en soulignant leur caractère idéal car, dans la pratique, les monastères n'ont pas pu tous bénéficier d'une situation aussi favorable. En effet, ces conditions étaient difficilement conciliables avec l'interdiction, édictée dans le canon V de la XXV ${ }^{\mathrm{e}}$ session du Concile de Trente les 3 et 4 décembre 1563, de fonder de nouveaux monastères en dehors des cités pour des raisons de sécurité, de subsistance matérielle et d'assistance spirituelle ${ }^{24}$. Les quartiers péricentraux non occupés, le long de la ceinture intérieure des derniers remparts édifiés, intéressèrent tout particulièrement les nouvelles communautés. Les faubourgs marécageux au nord et à l'ouest de la cité bordelaise attirèrent les ordres érémitiques.

Pourquoi les nouvelles communautés féminines se concentrèrent-elles dans le quart sud-ouest de la ville ? L'attrait exercé par la paroisse Sainte-Eulalie sur les ordres religieux s'explique par le faible prix du foncier lié à la médiocrité du sol et sa situation géographique. Le faubourg Sainte-Eulalie, qui était un des quartiers les plus tardivement intégrés dans l'enceinte fortifiée, avec la construction des nouveaux remparts au XIV ${ }^{\mathrm{e}}$ siècle, constituait un espace encore faiblement urbanisé au XVII ${ }^{\mathrm{e}}$ siècle, et probablement plus calme que les quartiers marchands ou portuaires. Pour mieux comprendre cette convergence de couvents dans un même quartier, on peut formuler l'hypothèse d'une logique de regroupement fonctionnel et identitaire. L'aspect fonctionnel de cette concentration d'établissements monastiques correspondrait à la volonté de créer un espace silencieux par l'appropriation d'un territoire et par l'acquisition progressive des biens fonciers situés autour de l'établissement originel, afin d'agrandir chaque enclos conventuel et d'éloigner les nuisances sonores ${ }^{25}$. Il se dégageait alors, sans conteste, un fort pouvoir symbolique d'un tel quartier où se concentrait plus du tiers des communautés régulières de Bordeaux. Cette hypothèse d'une logique de regroupement identitaire ou fonctionnel est corroborée par le fait que le monastère des Grands Carmes et celui des Augustins à Sainte-Eulalie, l'abbaye des Bénédictins à Sainte-Croix et le couvent des Dominicains à Notre-Dame de Puypaulin, qui

\footnotetext{
${ }^{22}$ Cela se vérifie à Paris, Caen ou Dijon et dans la plupart des grandes villes où la résistance du parcellaire urbain ancien s'avéra très forte jusqu'à la fin de l'Ancien Régime. D. Dinet, "Abbayes, couvents et monastères dans l'espace urbain des cités de l'Europe moderne» dans Les Passions d'un historien, op. cit., p. 1461-1472, ici p. 1470. Jean-Claude Perrot, Genèse d'une ville moderne : Caen au XVIII esiècle, Paris/La Haye, Mouton, 1975. Françoise Boudon, André Chastel, Hélène Couzy et Françoise Hamon, Système de l'architecture urbaine. Le Quartier des Halles à Paris, Paris, CNRS, 1977.

${ }^{23}$ Laurent Lecomte, Religieuses dans la ville, op. cit., p. 68 à 73.

${ }^{24}$ Ibid., p. 68.

${ }^{25}$ Laurent Lecomte a mis en évidence de telles stratégies de la part des Visitandines, Religieuses dans la ville, op. cit., p. 72.
} 
Pour citer cet article : LORIAUD Aude, « De vastes propriétés au cour des villes : le patrimoine urbain des communautés régulières à Bordeaux au milieu du XVIII ${ }^{\mathrm{e}}$ siècle ", Histoire, économie \& société, $\mathrm{n}^{\circ} 2 / 2019$ : L'emprise foncière des religieux dans l'espace urbain sous l'Ancien Régime, juin 2019, p. 23-46.

étaient toutes des fondations médiévales, semblent avoir constitué des pôles d'attraction, attirant à eux les maisons religieuses créées à l'époque moderne. Tout naturellement, les Dominicaines achetèrent une maison située près des Dominicains en 1629, avant leur transfert dans le faubourg Saint-Seurin en $1663^{26}$. Les Bénédictines s'installèrent en 1633 auprès des Bénédictins, les Minimettes à proximité des Minimes, ce qui pouvait faciliter - sans être systématique - la venue des confesseurs et des aumôniers dans les couvents de femmes appartenant à la même famille spirituelle. En résumé, l'implantation des religieux et des religieuses au XVII ${ }^{\mathrm{e}}$ siècle s'explique par les contraintes de l'espace urbain et des critères économiques, mais aussi par une logique de regroupement identitaire et fonctionnel combinant des raisons pratiques, spirituelles et symboliques. L'empreinte foncière des religieux dans les faubourgs méridionaux de Bordeaux se renforça encore avec la construction de nouveaux hôpitaux au cours des $\mathrm{XVII}^{\mathrm{e}}$ et XVIII ${ }^{\mathrm{e}}$ siècles dans cette partie de la ville. Plus rares, les implantations hors les murs, dans les faubourgs Saint-Rémi, Saint-Seurin et au-delà, traduisent la recherche de l'isolement et le besoin de vastes terrains constructibles encore disponibles au XVII ${ }^{\mathrm{e}}$ siècle. Ces nouveaux établissements dans les quartiers périphériques de Bordeaux accentuèrent le " polycentrisme religieux ${ }^{27}$ lentement constitué depuis le Moyen Âge avec les églises paroissiales, les monastères et les hôpitaux.

Dans certains cas, le site d'installation ne fut pas choisi librement. L'implantation de quelques établissements monastiques fut imposée, indirectement, par les élites qui soutenaient les nouvelles fondations religieuses et qui jouèrent ainsi un rôle dans l'aménagement urbain en offrant une parcelle ou un bâtiment. Par exemple, les jurats mirent un terrain à disposition des Minimes. Les Récollets, appelés par l'archevêque en 1602, furent installés par les jurats dans l'ancien noviciat des Cordeliers, au nord-ouest de la ville, à côté des Dominicains. L'archevêque fut le bienfaiteur des Chartreux et des Carmes déchaux. François de Sourdis donna une partie des terrains sur lesquels la Chartreuse fut édifiée. En outre, le cardinal de Sourdis demanda l'asséchement des marais situés entre le palais de l'archevêché et la Chartreuse ${ }^{28}$. La réalisation de la grande esplanade du Château Trompette, ordonnée par Mazarin dès 1653, et menée avec une relative liberté par le commissaire général des fortifications Louis Nicolas de Clerville et l'architecte-ingénieur Nicolas Desjardins, contraignit les Dominicaines de Sainte-Catherine, en 1663-1664, puis les Carmes déchaux, en 1669, à se déplacer. En effet, les Carmes déchaux installés près de l'église Saint-Christoly et ceux établis dans le faubourg des Chartrons formaient au départ une seule communauté. Le cardinal François de Sourdis avait attiré cet ordre dans

\footnotetext{
${ }^{26}$ AD Gironde, C 3852 : registre, $\mathrm{f}^{\circ} 24 \mathrm{v}^{\circ}-26 \mathrm{v}^{\circ}$, enregistrement et confirmation des lettres d'amortissement en faveur des dames religieuses du couvent de Sainte-Catherine de Sienne de 1'ordre de Saint-Dominique établies au faubourg Saint-Seurin données à Fontainebleau au mois d'octobre 1686.

${ }^{27}$ S. Lavaud, O. Pissoat, art. cit.

${ }^{28}$ Pierre Bernadau, Histoire de Bordeaux contenant la continuation des dernières histoires de cette ville, depuis 1675, époque où elles se terminent, jusqu'en 1838 ; précédée d'un résumé des principaux évènements rapportés dans ces mêmes histoires, depuis la fondation de Bordeaux [1837], Bordeaux, A. Castillon, 1839, p. 303-304.
} 
Pour citer cet article : LORIAUD Aude, « De vastes propriétés au cour des villes : le patrimoine urbain des communautés régulières à Bordeaux au milieu du XVIII ${ }^{\mathrm{e}}$ siècle », Histoire, économie \& société, $\mathrm{n}^{\circ} 2 / 2019$ : L'emprise foncière des religieux dans l'espace urbain sous l'Ancien Régime, juin 2019, p. 23-46.

son diocèse en achetant à leur intention, en 1626, une maison sur le quai des Chartrons ${ }^{29}$. L'extension du Château Trompette les obligea à quitter leur demeure, alors ils s'établirent en centre-ville, dans la rue qui fut rebaptisée des «Petits Carmes». Dès 1673, une partie des moines fut transférée dans une nouvelle maison édifiée dans le faubourg des Chartrons ${ }^{30}$. Un peu plus tard, en 1687, en réponse à l'appel du roi en 1685, de l'intendant et de l'archevêque, les Sœurs des écoles chrétiennes et charitables du Saint-Enfant-Jésus s'implantèrent à Bordeaux, où elles furent appelées Dames de la Foi. Leur venue, dans le but de convertir les jeunes filles protestantes, s'inscrivait dans le cadre de la politique royale d'unité religieuse, suite à la révocation de l'Édit de Nantes. La ville, qui s'était engagée à les loger, louait pour elles une maison ${ }^{31}$. Ainsi, élites religieuses et autorités municipales orientèrent la spatialisation des réguliers, à cette différence près que la jurade essaya de limiter leur emprise foncière et donc l'accroissement des biens de mainmorte, en les incitant à s'installer dans des bâtiments à réhabiliter ou des espaces urbains interstitiels ${ }^{32}$. La peur des autorités municipales face à l'accroissement des biens de mainmorte s'était généralisée dans les grandes villes de France au cours du XVII ${ }^{\mathrm{e}}$ siècle $^{33}$.

\section{L'emprise spatiale des religieux}

La surface des enclos conventuels variait beaucoup d'un monastère à l'autre. La figure 1 présentant la répartition des maisons conventuelles à Bordeaux au milieu du XVIII ${ }^{\mathrm{e}}$ siècle, réalisé à partir du plan de 1760 gravé par Lattré, fait apparaître un écart entre les communautés masculines et les communautés féminines. Le clergé régulier masculin détenait un plus grand nombre de bâtiments :

\footnotetext{
${ }^{29}$ B. Guillemain (dir.), Le Diocèse de Bordeaux, op. cit., p. 121-126. Les Carmes déchaux se virent également confier le service de la chapelle des Chartreux située sur le quai des Chartrons, qui devint la chapelle des « étrangers » et fut connue sous ce nom jusqu'à la Révolution.

${ }^{30}$ Gilles Sinicropi, «D'oraison et d'action ». Les Carmes déchaux en France aux XVII et XVIII ${ }^{e}$ siècles, SaintÉtienne, Publications de l'Université de Saint-Étienne, 2013, p. 57. Un arrêt royal ordonna la destruction du couvent des Carmes déchaux situé aux Chartrons afin d'agrandir le château Trompette (ADG, H 2714, Arrest du Conseil Royal, Bordeaux, 1669). Ce couvent, sous l'invocation de Saint-Louis, se déplaça alors dans le centreville. Un second, dédié à Notre-Dame du Salut, fut bâti en 1673 dans le quartier des Chartrons.

${ }^{31}$ Archives Municipales de Bordeaux Métropole, GG 978, registre de la Jurade du 13 décembre 1687 : « la maison du Sieur Lamothe avocat, située rue Maucoudinat, fut louée à raison de 500 livres par an et meublée aux dépens de la ville». De 1690 environ et jusqu'en 1710 au moins, les Sœurs des écoles chrétiennes et charitables du Saint-Enfant-Jésus demeurèrent dans un immeuble de la rue Désirade (actuelle rue Buhan, $\mathrm{n}^{\circ} 14$ ) puis, de 1772 jusqu'à la Révolution, dans la rue de Gourgue paroisse Saint-Éloy. Yves Poutet, «À propos d'un tricentenaire : Minimettes, Filles de la Foi, Dames de la Foi et Religieuses du Saint Enfant Jésus à Bordeaux », Revue Historique de Bordeaux, série 2, t. XII, 1963, p. 27-39.

${ }^{32}$ Notion de Géographie désignant de petits terrains restés vacants, ou non occupés, dans le bâti urbain.

${ }^{33}$ Le corps de ville de Rouen s'opposa à plusieurs reprises à la venue de nouvelles communautés régulières au $\mathrm{XVII}^{\mathrm{e}}$ siècle ou posa des conditions pour s'assurer de leur capacité à subvenir à leurs propres besoins. Par exemple, les Bénédictines du Saint-Sacrement firent face à plusieurs oppositions, en 1681, quand elles cherchèrent à acquérir l'Hôtel de Mathan dans la paroisse Saint-Godard de Rouen, qui comptait déjà dix maisons religieuses. Archives départementales de la Seine-Maritime, 76 H 1, requêtes et arrêt du roi du 8 mai 1681. Exemple développé dans ma thèse (déjà citée). On trouvera de nombreux exemples sur la Bourgogne et la Champagne dans D. Dinet, Religion et société, op. cit., t. 1, p. 153-167.
} 
Pour citer cet article : LORIAUD Aude, « De vastes propriétés au cour des villes : le patrimoine urbain des communautés régulières à Bordeaux au milieu du XVIII ${ }^{\mathrm{e}}$ siècle ", Histoire, économie \& société, $\mathrm{n}^{\circ} 2 / 2019$ : L'emprise foncière des religieux dans l'espace urbain sous l'Ancien Régime, juin 2019, p. 23-46.

seize $^{34}$, contre treize pour les femmes. L'enclos de chaque communauté religieuse se composait des édifices conventuels, de la chapelle et, le cas échéant, du pensionnat ou du noviciat et d'autres bâtiments liés au fonctionnement du couvent, parfois un jardin ou une cour. Or, à première vue, les enclos conventuels des religieux paraissent plus vastes que ceux des femmes. Cette impression résulte en réalité d'un biais de la représentation choisie sur les plans de Bordeaux gravés au XVIII siècle. Contrairement aux maisons religieuses d'hommes, les communautés féminines étaient simplement symbolisées par leur chapelle. Il faut confronter de nombreux plans $^{35}$, en particulier ceux de la Révolution, avant de reconstituer un tracé plus vraisemblable des enclos conventuels féminins (fig. 1). On s'aperçoit ainsi que le contraste genré apparaissant de prime abord doit en fait être nuancé. Par ailleurs, parmi les maisons religieuses d'hommes, neuf avaient été construites avant la fin du XVI siècle, et cinq d'entre elles avant la fin du XIII ${ }^{\mathrm{e}}$ siècle $^{36}$. À l'inverse, il ne subsistait à l'époque moderne aucun monastère féminin du Moyen Âge puisque celui des Clarisses, fondé en 1239, disparut en 1578. Or, les fondations du temps de la Réforme catholique ne donnèrent pas jour à des bâtiments aussi vastes que ceux du

\footnotetext{
${ }^{34}$ On dénombre quinze monastères d'hommes en ville et un seizième, le monastère des Chartreux, au-delà du faubourg Saint-Seurin, à la périphérie de la ville.

${ }^{35}$ Sources utilisées pour établir la carte des établissements réguliers à Bordeaux vers 1760 :

- Plan géométral de la ville de Bordeaux et de parties de ses Faubourgs, levé par les ordres de M. de Tourny, Intendant de la Généralité, par les Srs Santin et Mirail, 1755 (carte 97,5 x $127 \mathrm{~cm}$ ), Bibliothèque nationale de France, département Cartes et plans, GE DD-2987 (1489 B). URL : http://catalogue.bnf.fr/ark:/12148/cb405851474
}

- AN, N/III/Gironde/33/2, «Plan de la ville et faubourgs de Bordeaux, à Paris, chez Lattré graveur, rue SaintJacques au coin de celle de la Parcheminerie, à la ville de Bordeaux avec privilège du Roy, 1760 ».

- AN, N/II/Gironde/8/1-15, « Plan de l'abbaye Sainte-Croix de Bordeaux (XVII siècle)».

- AD Gironde, 2 Fi 2 : «Plan de la division du ci-devant monastère de La Magdelaine arrêté par le Directoire du District dressé sur les lieux par les soins de son architecte.»

- AD Gironde, 2 Fi 20 : «Plan de la partie invendue du ci-devant monastère des petites Carmélites de Bordeaux et dépendances, divisé en douze emplacements et sur lequel est projeté le prolongement de la rue Leiteyre et sa réunion à la rue Botanique, présenté à l'administration centrale du Département de la Gironde par le citoyen Roux, architecte de la Régie des Domaines Nationaux, le 2 Messidor an VII de la République française. »

- AD Gironde, 2 Fi 1127 : « Plan de l'ancien couvent des religieuses Annonciades de la ville de Bordeaux divisé en deux parties, levé et divisé par l'architecte de l'administration des Domaines », signé Roux (non daté, mais réalisé probablement l'an VII de la République, car ce même architecte a dressé le plan de l'ancien couvent des petites Carmélites cette année-là).

- AD Gironde, 2 Fi 6 : «Plan d'une partie de la commune de Bordeaux sur lequel sont tracés tous les domaines nationaux et les projets d'ouvertures de rues dont leur situation les rendent susceptibles, dans l'intérêt de la République (2 ventôse an II, soit en 1794)».

- AD Gironde, 2 Fi 1517: «Paroisses de Bordeaux, rue par rue », $2^{\mathrm{e}}$ moitié du XVIII" siècle. Volume relié, ensemble de plans manuscrits. 2 Fi 1517-3 : plan du couvent des Religieuses Notre-Dame ; 2 Fi 1517-9 : plan du couvent des Orphelines de Saint-Joseph ; 2 Fi 1517-23 : plan du couvent des Grandes Carmélites.

- Fonds patrimonial de la bibliothèque municipale de Bordeaux, Coll. Delpit, 13-27, «plan de deux emplacements faisant partie du ci-devant couvent des Ursulines situé rue Eulalie (vers 1793) ».

36 À savoir l'abbaye bénédictine de Sainte-Croix, les monastères des Grands Carmes, des Cordeliers de l'Observance, des Dominicains et des Augustins avant la fin du XIII siècle; celui des Pères de la Merci, seule fondation du XIV ${ }^{\mathrm{e}}$ siècle ayant perduré ; le couvent des Feuillants qui s'installèrent dans l'ancien hôpital des Antonins fondé au XIV e siècle, et le collège jésuite de la Madeleine à la fin du XVI e siècle; en dernier lieu, l'édifice des Récollets qui ne s'établirent à Bordeaux qu'au début du XVII ${ }^{e}$ siècle mais prirent place dans des bâtiments construits au XV $\mathrm{V}^{\mathrm{e}}$ siècle pour les Frères mineurs du couvent de Notre-Dame de Grâce. 
Pour citer cet article : LORIAUD Aude, « De vastes propriétés au cour des villes : le patrimoine urbain des communautés régulières à Bordeaux au milieu du XVIII ${ }^{\mathrm{e}}$ siècle ", Histoire, économie \& société, $\mathrm{n}^{\circ} 2 / 2019$ : L'emprise foncière des religieux dans l'espace urbain sous l'Ancien Régime, juin 2019, p. 23-46.

$\mathrm{XIII}^{\mathrm{e}}$ siècle, en raison du développement de l'urbanisation et de la densification des espaces urbains intra-muros. La disproportion des édifices conventuels masculins et féminins s'explique donc davantage par l'époque de construction.

Peut-on estimer l'emprise spatiale des couvents, à défaut de la mesurer avec précision ? La confrontation de différents plans de la ville de Bordeaux en 1733, 1754, 1760 et 1791, ainsi que des plans des couvents, a permis de parvenir à une évaluation de l'emprise foncière des réguliers à Bordeaux. Nos mesures, réalisées avec le S.I.G. Geoportail, ont abouti à un résultat avoisinant 23,4 hectares au sein de la ville close qui s'étendait sur 170 hectares environ. Par conséquent, la surface des enclos conventuels intra-muros représentait $13,7 \%$ de la cité bordelaise au XVIII ${ }^{\mathrm{e}}$ siècle. Ainsi, les réguliers s'étaient approprié une part importante du sol bordelais, sans atteindre le niveau de Rouen : 31,5 hectares ou $18,5 \%$ de la cité intra-muros vers 1730 avant les fermetures décidées par les Commissions des Secours et des Réguliers ${ }^{37}$.

À la fin de l'époque moderne, le bâti religieux paraissait omniprésent dans le tissu urbain bordelais. La forte occupation spatiale des communautés régulières, par leurs bâtiments conventuels et leurs biens locatifs, participait à la domination symbolique de l'Église catholique au $\mathrm{XVII}^{\mathrm{e}}$ et $\mathrm{XVIII}^{\mathrm{e}}$ siècles dans le paysage urbain, dans le sens où, pris séparément, chaque édifice n'avait pas d'autre vocation que celle d'abriter une communauté religieuse ou de rendre gloire au divin, mais ils manifestaient ensemble l'omniprésence de l'Église. Celle-ci se matérialisait avant tout par les clochers, éléments majeurs du paysage visuel et sonore de l'époque moderne. En outre, la masse des bâtiments ecclésiastiques dans le paysage - non seulement les couvents avec leurs hauts murs, mais aussi les églises et les chapelles, le palais de l'archevêque, les séminaires, les hôpitaux - exerçait un poids symbolique fort sur les représentations des populations fréquentant ces espaces urbains. Elle figurait la puissance du temporel de l'Église pour asseoir sa domination sur les autres religions et les autres courants de pensée. D'ailleurs, la construction de nombreux couvents en ville au début du XVII ${ }^{\mathrm{e}}$ siècle fut pensée comme un élément de reconquête des cités passées à la Réforme ${ }^{38}$. Le choix des décors, à l'intérieur des sanctuaires ou sur les façades des chapelles conventuelles, évoquant plus particulièrement l'ordre d'appartenance, imprégnait les conceptions des populations qui vivaient dans leur espace proche. La visibilité du religieux se définissait également par la présence de signes et de pratiques ${ }^{39}$. L'ouverture des églises conventuelles aux fidèles, les processions ${ }^{40}$, les décorations extérieures et les tapisseries

\footnotetext{
${ }^{37} \mathrm{~J}$ 'ai développé le cas rouennais dans ma thèse (déjà citée).

${ }^{38}$ Laurent Lecomte, Religieuses dans la ville, op. cit., p. 81.

39 Se référer aux travaux du second colloque EUDIREM sur La visibilité du religieux dans l'espace urbain européen (XIV $-X V I I I^{e}$ siècles) organisé par Gaël Rideau et Élise Boilet (19-21 septembre 2018, Centre Dupanloup, Orléans) porté par les universités de Tours et d'Orléans, avec la collaboration des universités de Florence et Lausanne. URL : https://eudirem.hypotheses.org/

40 « La construction d'un ordre en marche : les processions générales à Orléans au $18^{\mathrm{ème}}$ siècle » dans Gaël Rideau et Pierre Serna (dir.), Ordonner et partager la ville (XVII $-X I X^{e}$ siècles), Rennes, PUR, 2011, p. 137-154.
} 
Pour citer cet article : LORIAUD Aude, « De vastes propriétés au cour des villes : le patrimoine urbain des communautés régulières à Bordeaux au milieu du XVIII ${ }^{\mathrm{e}}$ siècle ", Histoire, économie \& société, $\mathrm{n}^{\circ} 2 / 2019$ : L'emprise foncière des religieux dans l'espace urbain sous l'Ancien Régime, juin 2019, p. 23-46.

déroulées à l'occasion de fêtes religieuses, participaient au rayonnement spirituel des différentes communautés régulières et à leur forte présence dans l'espace urbain, y compris les religieuses malgré la clôture stricte. Cette autre dimension de l'emprise foncière des réguliers est indirectement confirmée par la remise en question, par les Lumières, de la place même du religieux en ville, ou du moins ses expressions, au nom de la liberté de pensée, jusqu'à ce que l'Assemblée nationale décrète la fermeture des couvents et œuvre à la neutralisation de ces espaces en leur attribuant de nouvelles fonctions ${ }^{41}$.

\section{Le parc immobilier locatif des religieux dans l'espace urbain bordelais}

La présence des religieux dans l'espace urbain était protéiforme : outre les établissements religieux, accolés à une église et souvent agrémentés de jardins, le patrimoine urbain des communautés régulières se composait également de biens immobiliers qui étaient loués et généraient des revenus essentiels à la survie des monastères. Les revenus locatifs représentaient $28 \%$ du revenu global des communautés masculines de la cité bordelaise d'après Éric Suire ${ }^{42}$ et jusqu'à $45 \%$ des recettes des communautés féminines de la même ville ${ }^{43}$. Cette part eut tendance à s'accroître entre 1730 et 1760 pour les couvents féminins. Les Grandes Carmélites (ou Carmélites de Saint-Joseph) et les Bénédictines dépendaient largement de ces revenus locatifs, dont le montant atteignait 70\% de leur revenu global au milieu de la décennie $1750^{44}$. Les possessions à la campagne étaient nombreuses mais sont exclues de cette étude centrée sur l'emprise foncière des religieux dans l'espace urbain ${ }^{45}$. Pour quantifier celle-ci, il est nécessaire d'apprécier la composition et l'ampleur du patrimoine urbain des communautés en

\footnotetext{
${ }^{41}$ Bernard Cousin, Monique Cubells, René Moulinas, La Pique et la croix. Histoire religieuse de la Révolution française, Paris, Centurion, 1989, p. 182-184. Monique Cottret, « Le Carnaval de la Raison : combats autour de la visibilité des cultes en 1792-1793», communication lors du second colloque EUDIREM sur La visibilité du religieux dans l'espace urbain européen (XIV ${ }^{e}-X V I I I^{e}$ siècles).

42 Éric Suire, Les finances des religieux bordelais. Les Biens et revenus des communautés masculines du diocèse de Bordeaux, d'après les enquêtes fiscales de 1730 et 1760, T.E.R. sous la direction de Philippe Loupès, Université Bordeaux III, 1993, 2 vol., t. 1, p. 97.

${ }^{43}$ Ces données résultent de l'analyse que nous avons conduite, dans notre thèse, sur les déclarations de revenus des couvents féminins de Bordeaux de 1755 à 1760 (AD Gironde, G 830), complétées par des documents de 1790 pour les Filles Orphelines de Saint-Joseph (AD Gironde, G 627 et 4 L 129), en tenant compte des Dames de la Foi et les Filles du Bon Pasteur qui ne possédaient pas de maisons. On ne dispose pas de sources sur les revenus des Religieuses de Notre-Dame pour 1760, mais seulement pour 1729.

${ }^{44} \mathrm{AD}$ Gironde, G 830, déclarations des revenus et charges des communautés de religieuses du diocèse de Bordeaux : déclaration des Bénédictines de Bordeaux de 1755, déclaration des Grandes Carmélites de 1758.

${ }^{45}$ Cela ne signifie aucunement que les biens de campagne étaient peu importants. À titre d'exemple, les revenus issus des productions agricoles équivalaient à $60 \%$ des revenus totaux des communautés masculines du diocèse de Bordeaux, moyenne calculée à partir des déclarations de revenus de 1730 et 1760 . É. Suire, Les finances des religieux bordelais, op. cit., t. 1, p. 97. Voir aussi Marie-Pierre Dussaux, Les déclarations de revenus des communautés religieuses féminines du diocèse de Bordeaux (1730-1760), T.E.R. sous la direction de Philippe Loupès, Université Bordeaux III, 1991.
} 
Pour citer cet article : LORIAUD Aude, « De vastes propriétés au cour des villes : le patrimoine urbain des communautés régulières à Bordeaux au milieu du XVIII ${ }^{\mathrm{e}}$ siècle ", Histoire, économie \& société, $\mathrm{n}^{\circ} 2 / 2019$ : L'emprise foncière des religieux dans l'espace urbain sous l'Ancien Régime, juin 2019, p. 23-46.

dehors des bâtiments conventuels.

Le dénombrement des maisons de Bordeaux vers $1750^{46}$, exploité sous la forme d'une base de données, fournit le support de cette investigation. Ce dénombrement est construit sous la forme d'un tableau à quatre colonnes (propriétaires, locataires, maisons, échoppes). Les listes sont établies par régiment ${ }^{47}$, chacun divisé en compagnies, elles-mêmes subdivisées en dizaines, avec une mention précise des rues arpentées au fur et à mesure du recensement. C'est là tout l'intérêt de ce précieux document, bien qu'il ne soit pas daté. En effet, d'autres dénombrements furent régulièrement effectués mais il n'en subsiste que des états généraux, indiquant le nombre d'habitants par régiment pour aboutir à un recensement complet des Bordelais sans qu'ait été reporté, dans ces tableaux récapitulatifs, le détail des immeubles rue par rue, ni la liste des propriétaires et des locataires. L'intendant Tourny en fit vraisemblablement la demande en vue des grands travaux qu'il projetait, ce qui pourrait expliquer l'intérêt d'un dénombrement des maisons à la place d'un classique recensement. Il ne s'agissait peutêtre pas de connaître l'effectif total de la population ${ }^{48}$ mais de savoir quels étaient les propriétaires des biens qui se trouvaient potentiellement dans les espaces devant être réaménagés ${ }^{49}$. Sinon, il est fort possible aussi que ce dénombrement ait eu une vocation fiscale. Cet état des propriétaires et des locataires à Bordeaux date du milieu du XVIII ${ }^{\mathrm{e}}$ siècle $^{50}$, très certainement entre 1750 et 1752 . La certitude

\footnotetext{
${ }^{46}$ AD Gironde, C 1276, Dénombrement des propriétaires et locataires des maisons et échoppes de la ville de Bordeaux par régiment, vers 1750-1752.

${ }^{47}$ Régiments Saint-Maixant dans la ville, Saint-Maixant hors la ville (faubourg Saint-Seurin), Sainte-Eulalie, Saint-Éloy, Saint-Michel et Saint-Pierre. Ce dénombrement a cependant une limite : l'absence de données pour le régiment Saint-Rémi, ce qui a pu conduire, dans nos résultats, à une sous-estimation des biens des réguliers dans la partie nord de la ville, bien que nous ayons tenté de combler cette lacune en recourant à la liste des biens que possédaient les Carmes des Chartrons grâce aux déclarations de revenus des Carmes des Chartrons de 1730 et 1760 transcrites dans É. Suire, Les finances des religieux bordelais, op.cit., t. 2, p. 54-55. Pour comprendre l'organisation et l'importance des régiments, voir Claude C. Sturgill : « Une source de l'histoire sociale urbaine : le rôle des miliciens de Bordeaux de 1722 », Annales du Midi, t. 86, n 117 , 1974, p. 165-180. URL : https://www.persee.fr/doc/anami_0003-4398_1974_num_86_117_4865

${ }^{48}$ Le 22 octobre 1747, l'intendant Louis-Urbain Aubert chevalier marquis de Tourny donna des instructions «pour faire le dénombrement exact du nombre, qualité, profession et demeure des habitants de la ville et fauxbourgs de Bordeaux » (AD Gironde, C 1270). Or, ces instructions ne coïncident pas avec la forme adoptée pour le dénombrement classé en C 1276. Quant au dénombrement effectué en 1748, sans doute très précis si toutes les instructions ont été suivies, il n'a pas été retrouvé. Seuls quelques états généraux sous forme de tableaux récapitulatifs ont été conservés pour estimer la population totale de Bordeaux. L'état général du 4 mars 1748 signé Pudeffer (AD Gironde, C 1270) précise le nom des colonels et capitaines de régiments ; or ceux-ci ne sont pas exactement les mêmes que ceux ayant établi le dénombrement classé C 1276.

${ }^{49}$ Le plus grand des projets de réaménagement menés par l'intendant Louis-Aubert-Urbain de Tourny débuta en 1754 : il fit élever une façade uniforme d'environ 300 maisons depuis l'hôtel de la Douane jusqu'à la porte de la Grave en trois ans pour l'embellissement du port. Après avoir transmis en 1757 sa charge à son fils, Claude Louis Aubert de Tourny, il continua à traiter avec lui des affaires de Guyenne et à diriger les travaux d'embellissement depuis Paris. Tous les plans lui étaient communiqués et il échangeait par correspondance avec les artistes Portier, Soufflot, Cochin, Dupuy, Lemoine. Pierre Bernadau, Histoire de Bordeaux, op. cit., p. 113-117 ; Michel Lhéritier, Tourny, intendant de Bordeaux, Paris, Félix Alcan, 1920, t. 2, p. 521-534.

${ }^{50}$ Adrien Martinez propose la date de 1765, à la suite d'Alexandre Nicolaï, mais notre analyse nous conduit à préférer plutôt une datation comprise entre 1750-1752. Voir Adrien Martinez, Sainte-Eulalie. Un quartier de Bordeaux à la fin de l'Ancien Régime (vers 1765-vers 1790), mémoire de Master 2 sous la direction de Michel
} 
Pour citer cet article : LORIAUD Aude, « De vastes propriétés au cour des villes : le patrimoine urbain des communautés régulières à Bordeaux au milieu du XVIII ${ }^{\mathrm{e}}$ siècle ", Histoire, économie \& société, $\mathrm{n}^{\circ} 2 / 2019$ : L'emprise foncière des religieux dans l'espace urbain sous l'Ancien Régime, juin 2019, p. 23-46.

que ce document est antérieur à 1752 se fonde sur le fait que l'intendant Louis-Urbain-Aubert de Tourny ordonna la construction de la porte de l'hôtel de la Monnaie en 1752. Pour faciliter la communication de l'hôtel de la Monnaie avec le couvent des Capucins et la porte de ville du même nom, la ruelle qui s'étendait en cet endroit, trop étroite, fut élargie et divisée en deux parts, sous les noms des rues Française et Marbotin ${ }^{51}$; or, ces rues n'existaient pas à l'époque où fut réalisé le recensement. En outre, ces déductions chronologiques reposent sur la confrontation de ce document avec les baux locatifs des Grandes Carmélites ${ }^{52}$. Ainsi, Jacob Gomes Athias, marchand portugais et locataire rue Bouhaut ${ }^{53}$ de 1729 à 1752, figure sur le dénombrement du régiment de Sainte-Eulalie, ce qui confirme qu'il est antérieur à 1752. Pierre Larroque, porteur de chaise et locataire des Carmélites rue du Canon, figure également dans le dénombrement; or, il occupa cette maison à partir de 1741, et décéda à une date inconnue comprise entre 1756 et 1762, date à laquelle sa veuve reçut l'injonction de quitter les lieux ${ }^{54}$. Troisièmement, Thérèse Sauvage veuve de Jean Seurin, également présente dans le dénombrement, loua $^{55}$ aux Carmélites une maison avec chai et grenier située dans l'enclos de leur couvent, près de la porte Dijeaux, de 1750 à 1763. Une précision donnée dans le bail signé en 1750 indique qu'il s'agissait d'une maison que les religieuses avaient fait bâtir depuis peu. En dernier lieu, l'hôtel de M. Gradis, édifié à partir de 1750 sur les fossés de 1'Hôtel-de-Ville ${ }^{56}$, est mentionné dans le dénombrement. En résumé, l'état des propriétaires et des locataires à Bordeaux classé C 1276 aux archives départementales de la Gironde n'a pu être réalisé qu'entre 1750 et 1752.

La dispersion et la diversification des biens locatifs : des stratégies d'acquisitions ?

À partir de ce dénombrement des maisons bordelaises par régiment datant du milieu du $\mathrm{XVIII}^{\mathrm{e}}$ siècle, il a été possible de représenter la dispersion des biens locatifs des réguliers dans la cité bordelaise (fig. 3). Dans les analyses qui suivent, la division en régiments a été privilégiée par rapport

Figeac, Bordeaux, Université Michel de Montaigne, 2013 ; Alexandre Nicolaï, La population de Bordeaux au XVIII siècle (1700-1801), Bordeaux, G. Gounouilhou, 1906.

${ }^{51}$ Une délibération des jurats du 15 juillet 1752, sur la proposition de Tourny, ordonna l'ouverture d'une nouvelle porte de ville : la porte de la Monnaie, dont le nom vient du fait qu'on construisit en même temps l'atelier monétaire auprès d'elle. Pierre Bernadau, Histoire de Bordeaux, op. cit., p. 111-112.

52 AD Gironde, H 2745-2747, Grandes Carmélites, biens immobiliers, baux, pièces de procédure.

${ }^{53}$ AD Gironde, H 2745, Grandes Carmélites, baux couvrant la période de 1729 à 1752 souscrits par Jacob Gomes Athias.

${ }^{54}$ AD Gironde, H 2745, Grandes Carmélites, baux couvrant la période 1741-1752 conclus avec Pierre Larroque pour une maison sise rue du Canon appartenant aux Grandes Carmélites ; signification, par Jean Valance huissier audiencier au siège des Eaux et forêts de Guyenne, en date du 18 octobre 1762, sommant la veuve de Pierre Larroque de payer sans délai aux Grandes Carmélites la somme de 172 livres pour arrérages de loyers de la maison qu'elle a occupée rue du Canon en vertu d'un contrat de location consenti en faveur de feu Larroque le 19 mai 1756, avec injonction de quitter et vider la maison.

${ }_{55}^{50}$ AD Gironde, H 2747, Grandes Carmélites, biens immobiliers, baux, pièces de procédure.

${ }^{56}$ Base Mérimée des monuments historiques : Notice « Hôtel Gradis », référence PA00083195. URL : http://www.culture.gouv.fr/public/mistral/merimee_fr?ACTION=CHERCHER\&FIELD_1=REF\&VALUE_1=P A00083195 
Pour citer cet article : LORIAUD Aude, « De vastes propriétés au cour des villes : le patrimoine urbain des communautés régulières à Bordeaux au milieu du XVIII ${ }^{\mathrm{e}}$ siècle ", Histoire, économie \& société, $\mathrm{n}^{\circ} 2 / 2019$ : L'emprise foncière des religieux dans l'espace urbain sous l'Ancien Régime, juin 2019, p. 23-46.

au maillage paroissial car l'effectif total des maisons et échoppes, indiqué pour chaque régiment, permet de calculer la part des bâtiments possédés par les réguliers. Les proportions les plus élevées de biens détenus par les réguliers, hors bâtiments conventuels, se trouvaient à Sainte-Eulalie (7,6\% du total des maisons et échoppes de ce quartier régimentaire), Saint-Éloy (5,3\%) et Saint-Michel (4,8\%). Ce constat accroît le poids de l'emprise foncière dans la partie sud de la ville, où l'on a mis en évidence la forte densité des établissements conventuels.

L'étude de la dispersion des biens religieux révèle des propriétés concentrées aux abords du couvent dans la majeure partie des cas (fig. 5). On remarque que le taux de concentration foncière des biens locatifs était égal ou supérieur à $75 \%$ pour seize communautés régulières sur les vingt-trois en possédant. Une stratégie très simple présidait aux investissements locatifs des réguliers : 1'appropriation de l'espace proche, parfois par simple pragmatisme, parfois dans le but d'agrandir ultérieurement l'enclos monastique. En effet, l'acquisition progressive des maisons situées autour de l'enclos originel aboutissait à la constitution d'un îlot conventuel. On peut définir ce dernier comme un espace centré sur un couvent, regroupant autour de lui, dans des limites proches et cohérentes, les biens qu'il possède. L'unification d'un îlot par un unique propriétaire ecclésiastique, englobant parfois une partie du sol public, notamment les voies de passage, a été observée pour la ville de Naples du XVI ${ }^{\mathrm{e}}$ au XVIII ${ }^{\mathrm{e}}$ siècle par Brigitte Marin. Ce processus était désigné par l'expression «fare isola $»^{57}$, littéralement « faire/construire une île ». Différents cas de figure peuvent être distingués grâce à la construction d'une typologie des propriétés des réguliers (tableau 1). Dans le premier type, «Propriété fortement concentrée », qui concerne dix communautés, le taux de concentration des biens locatifs égale $100 \%$ pour huit d'entre elles, exception faite des Bénédictins dont le taux de concentration était inférieur. Cependant, la totalité de leurs biens était localisée dans leur quartier. Dans cette catégorie, le cas des Petites Carmélites (ou Carmélites de l'Assomption) est sans aucun doute le plus emblématique car son patrimoine, le plus grand de toutes les communautés de ce premier type, se composait de 36 biens, tous situés dans les rues adjacentes au couvent. 19 de leurs échoppes se trouvaient contre les remparts clôturant leur couvent, ce qui est bien le signe de leur volonté d'optimiser les interstices non occupés de l'enclos conventuel. À l'opposé, les propriétés dont la dispersion était très large, sur trois ou quatre quartiers, étaient celles des Jésuites, des Bénédictines et des Grandes Carmélites. La représentation de la dispersion des biens des Bénédictines et des Jésuites est éclairante car ces deux communautés se trouvaient à la tête des plus grands patrimoines urbains (fig. 2). Cela dit, un grand patrimoine n'était pas toujours synonyme de dispersion foncière large. Deux autres types intermédiaires sont observables : les communautés, souvent bien dotées, dont le patrimoine était réparti sur deux ou trois paroisses mais dont $80 \%$ des biens étaient localisés aux abords du couvent ; et enfin celles qui échappaient totalement à la

57 Brigitte Marin, «Espaces sacrés, concessions de terrains publics et arrangements urbains à Naples au XVIII ${ }^{\mathrm{e}}$ siècle », dans B. Dumons, B. Hours (dir.), Ville et Religion, op. cit., p. 20. 
Pour citer cet article : LORIAUD Aude, « De vastes propriétés au cour des villes : le patrimoine urbain des communautés régulières à Bordeaux au milieu du XVIII ${ }^{\mathrm{e}}$ siècle ", Histoire, économie \& société, $\mathrm{n}^{\circ} 2 / 2019$ : L'emprise foncière des religieux dans l'espace urbain sous l'Ancien Régime, juin 2019, p. 23-46.

tendance à la concentration car leurs biens, même s'ils n'étaient pas nombreux, se trouvaient dispersés dans deux paroisses et dans différentes rues. Indéniablement, les réguliers avaient tendance à renforcer en priorité leur emprise spatiale dans leur quartier ou dans des rues où ils possédaient déjà des biens.

Est-il juste de parler de « stratégie » ou de « politique d'acquisition » au sujet des propriétés des réguliers, sachant qu'elles étaient en partie constituées d'héritages ? Il faudrait réaliser une étude précise, à l'aide des minutes notariales, afin de déterminer ce qui avait été acquis et ce qui avait été hérité par chaque communauté religieuse. Cependant, on sait que, dans la mesure où les donations se tarirent un peu au XVIII ${ }^{\mathrm{e}}$ siècle par rapport au siècle précédent ${ }^{58}$, l'extension du parc foncier au XVIII ${ }^{\mathrm{e}}$ siècle se réalisa principalement par des investissements, profitant ainsi du formidable développement urbain de la fin de l'Ancien Régime, comme l'a montré aussi Preston Perluss pour les communautés régulières de Paris et Lyon $^{59}$. Malgré tout, cette extension fut limitée car l'obligation de payer les droits d'amortissement et de nouvel acquêt exigibles sur les biens immobiliers et les terres des gens de mainmorte, conformément à l'édit de 1689, entraina l'arrêt presque total des acquisitions foncières dans les années suivantes. Certaines communautés furent obligées d'emprunter pour s'acquitter de ces droits si élevés ${ }^{60}$.

De manière plus sûre, on peut qualifier de stratégie d'investissement la préférence pour la construction d'échoppes. Le parc locatif des Bénédictines, des Petites Carmélites et des Carmes déchaux des Chartrons se composait à plus de 70\% d'échoppes ; contre $47 \%$ pour les Minimes et $40 \%$ pour les

\footnotetext{
${ }^{58} \mathrm{La}$ majeure partie des donations datent généralement des premiers temps de la fondation. La rareté, au XVIII ${ }^{e}$ siècle par rapport au XVII ${ }^{e}$ siècle, des testaments comme des sources attestant de legs pieux nous est apparue par la fréquentation assidue des archives des communautés féminines de Bordeaux. Éric Suire a observé la raréfaction des dons et legs aux Grands Carmes et aux Minimes bordelais d'après leurs obituaires. É. Suire, «Les religieux français face à la faillite du système financier de Law» dans Laurent Coste et Sylvie Guillaume (dir.), Élites et crises du XVI au XXIe siècle, Paris, Armand Colin, 2014, p. 377-390, ici p. 390. Cette tendance a aussi été soulignée par Régis Bertrand pour les chartreuses de Provence, au XVIII siècle par rapport à un $\mathrm{XVII}^{\mathrm{e}}$ siècle très favorable. "Aperçu sur les finances des chartreuses provençales aux XVII et XVIII siècles », dans Michel Aubrun, Gabriel Audisio, Bernard Dompnier, André Gueslin, Entre idéal et réalité. Finances et religion du Moyen Âge à l'époque contemporaine, Clermont-Ferrand, Publications de l'Institut d'Études du Massif Central, 1994, p. 208, cité par É. Suire, art. cit., p. 390.

${ }_{59}$ Preston Perluss, Les communautés régulières d'hommes de la rive gauche dans l'univers parisien au $X V I I I^{e}$ siècle, thèse de doctorat d'histoire moderne sous la direction de Jean-Pierre Poussou, Université Paris IV Sorbonne, 2003, 2 vol. Id., «French monastic urban wealth: methodological overview and preliminary observations », Discusso in occasione del convegno CRESO «Ordini Regolari e società civile in Piemonte fra XVI e XIX secolo » (Torino, 3-5 Iuglio 2014). URL : http://www.religious-orders-piedmont.polito.it/news.html ${ }^{60}$ En effet, les supérieurs des communautés religieuses furent étonnés par la brutalité soudaine de ces taxes car il fallut régler des droits sur toutes les propriétés acquises depuis l'amortissement général accordé en 1641, ou depuis les derniers amortissements particuliers accordés. D. Dinet, Religion et société, op. cit., t. 1, p. 377. Par exemple, à Bordeaux, les Ursulines durent emprunter en 1693 à M. Montaigu 1818 livres 3 sols 6 deniers pour payer les 11706 livres 1 sol 10 deniers qu'elles devaient au Trésor Royal (AD Gironde, G 628, liasse des Ursulines de Bordeaux : déclaration de revenus de 1717 avec les pièces jointes, dont la copie des quittances du Trésor Royal en 1693-1694). L'année 1689 et le début de la décennie 1690 marquèrent un grand tournant pour les communautés religieuses post-tridentines entre une période de relative suffisance et le début d'un déclin. Elizabeth Rapley, $A$ Social History of the Cloister: Daily Life in the Teaching Monasteries of the Old Regime, Montreal \& Kingston/London/Ithaca, McGill-Queen's Press, 2001, p. 39.
} 
Pour citer cet article : LORIAUD Aude, « De vastes propriétés au cour des villes : le patrimoine urbain des communautés régulières à Bordeaux au milieu du XVIII ${ }^{\mathrm{e}}$ siècle ", Histoire, économie \& société, $\mathrm{n}^{\circ} 2 / 2019$ : L'emprise foncière des religieux dans l'espace urbain sous l'Ancien Régime, juin 2019, p. 23-46.

Jésuites (fig. 6) ${ }^{61}$. Cette composition atypique relevait parfois d'opérations d'investissements de grande envergure, à l'image des Bénédictines qui achetèrent 32 échoppes sur le chemin de Bordes, outre les 7 échoppes de la rue Carpenteyre, ou bien les Minimes dont les 10 échoppes étaient situées sur le chemin de Pessac, ou encore les Jésuites qui possédaient, entre autres, 8 échoppes dans les rues Judaïque et du Petit Ponlong. Ce sont des éléments qui attestent de l'intérêt porté aux quartiers péri-urbains. Cependant, on ne remarque pas, du moins au milieu du XVIII ${ }^{\mathrm{e}}$ siècle, la construction de grands complexes dans le faubourg Saint-Seurin, un quartier pourtant en expansion ${ }^{62}$. Ce sont plutôt les quartiers Saint-Éloy et Saint-Michel qui intéressèrent les réguliers comme terrains d'investissements. Ils possédaient en effet $28,6 \%$ des échoppes du quartier régimentaire Saint-Éloy et 12\% à Saint-Michel. Les maisons possédées par les religieux et religieuses étaient souvent en ruine ${ }^{63}$, ce qui entraînait de lourdes charges ${ }^{64}$ pour les maintenir dans un état correct. À l'inverse, les échoppes louées à des boutiquiers ou des artisans, de dimensions très modestes ${ }^{65}$, étaient peu coûteuses à construire et nécessitaient très peu d'aménagement et d'entretien. Elles intéressaient une clientèle populaire nombreuse. Par conséquent, l'investissement dans l'immobilier de commerce constituait une bonne alternative aux maisons de rapport en raison des moindres charges qui pesaient sur les échoppes. Ces investissements s'avéraient généralement rentables, sauf quand les plus pauvres partaient sans payer ${ }^{66}$. Quant aux Bénédictins, ils se distinguaient par la

${ }^{61}$ Seules les communautés possédant des échoppes figurent sur ce graphique (fig. 6), exception faite des Dominicaines de Sainte-Catherine et des Ursulines qui ont été exclues en raison de la non-représentativité des données les concernant en comparaison des autres communautés. En effet, le parc immobilier urbain des Dominicaines se composait de 50\% d'échoppes mais cela correspondait à seulement 2 échoppes sur 4 biens. Quant aux Ursulines, leur parc immobilier était composé de $20 \%$ d'échoppes mais il s'agissait en fait d'un unique bien sur 5 au total.

${ }^{62}$ Seule exception : les Carmes déchaux y possédaient 10 maisons et 3 échoppes, ce qui n'était pas négligeable. AD Gironde, C 1276, Régiment de Saint-Mexant faubourg Saint-Seurin. Après 1740, la ville s'étendit principalement au nord-ouest, au nord et sur les quais. Voir par exemple Philippe Maffre, Construire à Bordeaux au XVIII siècle : les frères Laclotte, architectes en société, Bordeaux, Société archéologique de Bordeaux, 2013.

${ }^{63}$ Les Religieuses de Notre-Dame, dans la même ville, déploraient posséder des maisons qui risquaient de s'écrouler à tout moment, à la fin du XVII ${ }^{\mathrm{e}}$ siècle (AD Gironde, H 2141, Biens immobiliers des Filles de NotreDame : déclaration des biens et revenus daté du 20 décembre 1689). Les Petites Carmélites louaient à la fin des années 1750 « neuf petites maisons vieilles et délabrées et vingt-trois mauvaises échoppes avec une masure d'un ancien moulin à vent » à Catherine Ransonnet et « deux vieilles maisons délabrées, une assez grande, l'autre petite avec un chai » à la demoiselle Lugayac d'après les baux du 9 juillet 1757 et du 3 octobre 1758, enregistrés par le notaire Séjourné, mentionnés dans la déclaration des biens et revenus des Petites Carmélites datée du 10 octobre 1758 (AD Gironde, G 830, déclarations de revenus des communautés de religieuses du diocèse de Bordeaux).

${ }^{64}$ Par exemple, la maison située rue du Faignas possédée par les Grandes Carmélites du monastère de Saint-Joseph prouve la rentabilité nulle de certains immeubles en ruine. Les religieuses décidèrent de passer un marché avec l'architecte Alary le 18 août 1753 pour reconstruire ce bien. Dans un mémento, l'une d'entre elles précise que cette maison « donnait 100 livres qu'il fallait employer tous les ans en réparations, étant en danger chaque jour de s'écrouler ». AD Gironde, H 2745, Grandes Carmélites, actes d'acquisitions, mémento daté du 18 août 1753.

${ }^{65}$ À titre d'exemple, les Annonciades possédaient cinq échoppes d'une surface moyenne de $25 \mathrm{~m}^{2}$. Dans un mémoire d'ouvrages, il est précisé que trois d'entre elles mesuraient «sur le devant 61 pieds sur 12 pieds 8 pouces » et les deux dernières avaient « en longueur sur le devant 37 pieds sur 12 pieds 2 pouces », AD Gironde, H 2078, Annonciades, mémoire d'ouvrages pour la toise des murailles des cinq échoppes bâties, s.d.

${ }^{66}$ AD Gironde, G 830, États des communautés de filles du diocèse de Bordeaux : déclaration des Bénédictines de Bordeaux datée du 13 mars 1759. Les Bénédictines louaient verbalement dix petites échoppes, dans la rue Carpenteyre, pour le prix de 90 livres chacune par an, soit 900 livres au total. Mais les religieuses précisaient que 
Pour citer cet article : LORIAUD Aude, « De vastes propriétés au cour des villes : le patrimoine urbain des communautés régulières à Bordeaux au milieu du XVIII ${ }^{\mathrm{e}}$ siècle ", Histoire, économie \& société, $\mathrm{n}^{\circ} 2 / 2019$ : L'emprise foncière des religieux dans l'espace urbain sous l'Ancien Régime, juin 2019, p. 23-46.

stratégie d'investissement qu'ils adoptèrent : ils choisirent d'investir dans des moyens de production, attitude qui parait en phase avec l'essor du libéralisme à cette période. Outre le moulin possédé par l'abbé depuis plusieurs siècles, l'abbaye de Sainte-Croix était propriétaire au milieu du XVIII ${ }^{\mathrm{e}}$ siècle de trois raffineries situées rue du moulin, dans le régiment de Saint-Michel, louées aux sieurs Neyrac, Archambeau et Arquier ${ }^{67}$. En définitive, les réguliers ne cherchaient pas seulement à acquérir ou faire construire des immeubles dans leur espace proche; ils s'efforçaient de réaliser des investissements plutôt rentables, permettant notamment de contrebalancer les lourdes charges qui pesaient sur d'autres héritages médiocres.

\section{Des critères de différenciation?}

Comment expliquer la taille très inégale des propriétés des réguliers? Si l'ancienneté des communautés religieuses est parfois synonyme d'un patrimoine comportant une part notable de domaines ruraux, dont l'acquisition remontait souvent au Moyen Âge, il serait erroné de croire qu'il y aurait une corrélation entre la date de fondation et la superficie du patrimoine urbain. Les communautés fondées tardivement n'étaient pas forcément les moins bien dotées, et inversement. Arrivés en 1572 pour tenir le collège de la Madeleine, les Jésuites firent construire ensuite un noviciat en 1607, une maison professe en 1624, et peu à peu la Compagnie de Jésus devint la communauté masculine à la tête du plus grand parc immobilier locatif dans la ville de Bordeaux, bien plus vaste que celui des fondations médiévales, comme les Augustins et les Dominicains. Les Ursulines et les Religieuses de Notre-Dame, qui furent les deux premières maisons de religieuses issues du mouvement de fondation post-tridentin, ne faisaient pas partie des communautés féminines à la tête d'un patrimoine conséquent en ville. Par ailleurs, celui des Religieuses de Notre-Dame, qui se composait de treize maisons, n'était pas comparable à celui des Ursulines qui n'en avaient que cinq. Le nombre de possessions urbaines variait assez souvent en fonction de l'effectif de la communauté régulière, mais pas systématiquement. Les dots d'entrées en religion ont contribué à la dynamique des investissements fonciers, mais de nombreux exemples montrent le caractère aléatoire de ce lien. Par exemple, le couvent de La Magdelaine, qui accueillait 41 religieuses en 1727, ne disposait que de quatre maisons et subsistait davantage du revenu des pensions. Des couvents très attractifs comme celui des Ursulines, peuplé de 49 religieuses en 1727 , des Visitandines (50 à la même date) ou des Dominicaines de Sainte-Catherine (39), ne possédaient pas plus de cinq biens, comme la petite communauté des Filles Orphelines de Saint-Joseph qui comptait une

ces échoppes étaient louées « à de pauvres artisans qui mett[ai]ent souvent la clef sous la porte à raison de quoi la communauté [«tait] en perte d'une partie des loyers ». Elles dressaient le même constat au sujet des vingt-huit petites échoppes situées près du pont du Guit, hors les murs, dans le faubourg Sainte-Croix.

${ }^{67}$ AD Gironde, C 1276, Dénombrement des maisons de Bordeaux, Régiment de Saint-Michel. 
Pour citer cet article : LORIAUD Aude, « De vastes propriétés au cour des villes : le patrimoine urbain des communautés régulières à Bordeaux au milieu du XVIII ${ }^{\mathrm{e}}$ siècle ", Histoire, économie \& société, $\mathrm{n}^{\circ} 2 / 2019$ : L'emprise foncière des religieux dans l'espace urbain sous l'Ancien Régime, juin 2019, p. 23-46.

quinzaine de sœurs.

Les monastères d'hommes et de femmes disposaient-ils de propriétés comparables ? Parmi les six communautés les mieux dotées, avec plus de trente bâtiments en location, on trouve autant de communautés de femmes que d'hommes (fig. 4). Pourtant, on constate que $60 \%$ des communautés masculines avaient plus de dix biens (valeur médiane de la série de données), contre seulement 38\% de communautés féminines. Par ailleurs, la superficie possédée par les couvents de femmes équivalait la plupart du temps à celle des communautés régulières d'hommes (fig. 7). À Sainte-Eulalie, 3,5\% du bâti était possédé par les religieuses et 4,1\% par les religieux ; à Saint-Maixant dans la ville, respectivement $1,6 \%$ et $1,5 \%$; à Saint-Michel, $2,8 \%$ et 2\% ; exceptions faites du régiment de Saint-Éloy où les moniales propriétaires étaient plus présentes que les hommes (3,9\% contre 1,4\%), comme à Saint-Pierre $(1,3 \%$ contre $0,3 \%$ ). À l'inverse, dans le régiment Saint-Maixant hors la ville, seulement 0,3\% du bâti revenait aux moniales contre $2 \%$ pour les religieux. Par conséquent, les déductions pouvant être contradictoires selon la méthode d'analyse, on n'observe pas de réels écarts significatifs.

Enfin, le cumul de plusieurs critères explique que les Dames de la Foi et les Filles du Bon Pasteur n'aient détenu aucun patrimoine foncier. Ces communautés de femmes, qui furent les deux fondations féminines les plus tardives - les Dames de la Foi s'établirent en 1687 et les Filles du Bon Pasteur en 1725 - furent en outre pénalisées par leur petite taille, avec onze sœurs environ chez les premières et douze chez les secondes. Il faut par ailleurs prendre en compte les spécificités de leur statut : elles ne relevaient pas d'un ordre ni d'une congrégation mais d'un institut séculier.

\section{Mettre en perspective l'emprise foncière des religieux}

Les conclusions précédentes doivent être mises en perspective afin de discuter la réalité de la domination des réguliers dans le bâti urbain. On ne peut pas, hélas, mesurer précisément la part exacte de leur emprise foncière totale, en raison de l'absence d'archives sur la surface de leurs biens locatifs. On peut donc seulement rappeler que la surface des enclos conventuels représentaient 13,7\% de l'espace urbain intra-muros, et que les réguliers détenaient en outre presque 5\% des maisons et échoppes de la ville (tableau 2). Cette situation se rapprocherait alors de celle de Dijon ${ }^{68}$ ou Caen ${ }^{69}$.

L'analyse de la proportion de l'ensemble des biens ecclésiastiques dans chaque régiment permet de se rendre compte que celle-ci variait peu selon les quartiers : entre $6,5 \%$ et $11,9 \%$ du bâti, exception faite de Saint-Maixant dans la ville, où cette part atteignait 21,4\% en raison des propriétés des chanoines (fig. 8). Philippe Loupès a montré combien les chapitres de Saint-André et de Saint-Seurin étaient de

\footnotetext{
${ }^{68}$ En incluant les maisons louées, Dominique Dinet estime que les communautés régulières de Dijon disposaient de 20\% du territoire de la ville. D. Dinet, Religion et société, op. cit., t. 1, p. 268.

${ }^{69}$ Selon une autre méthode de calcul, la proportion détenue par les réguliers à Caen, en valeur de l'ensemble de la propriété immobilière, atteignait près de 20\%. J.-C. Perrot, Genèse d'une ville moderne, Caen, op. cit., p. 619 cité par D. Dinet, Religion et société, op. cit., t. 1, p. 270.
} 
Pour citer cet article : LORIAUD Aude, « De vastes propriétés au cour des villes : le patrimoine urbain des communautés régulières à Bordeaux au milieu du XVIII ${ }^{\mathrm{e}}$ siècle ", Histoire, économie \& société, $\mathrm{n}^{\circ} 2 / 2019$ : L'emprise foncière des religieux dans l'espace urbain sous l'Ancien Régime, juin 2019, p. 23-46.

gros propriétaires fonciers ${ }^{70}$. Leur endettement chronique les empêcha néanmoins de continuer à accrôtre leur patrimoine aux $\mathrm{XVII}^{\mathrm{e}}$ et $\mathrm{XVIII}^{\mathrm{e}}$ siècles. La seigneurie de Saint-Seurin apparaissait solidement implantée dans le vieux centre, au nord de la cathédrale Saint-André et de la collégiale Saint-Seurin, tandis que les fiefs de Saint-André se trouvaient concentrés dans la périphérie méridionale. Malgré tout, dans l'ensemble des recettes de ces grands chapitres urbains, les biens locatifs rapportaient moins que la perception des droits de censive sur près d'un millier d'immeubles, soit environ $20 \%$ de l'espace urbain à la fin XVII ${ }^{\mathrm{e}}$ siècle ${ }^{71}$. Comparé à celui du clergé séculier, le patrimoine urbain des religieux ne constituait pas une mainmise sur l'espace urbain bordelais. L'exemple du territoire du régiment de Saint-Maixant dans la ville est éclairant. Il s'y trouvait une abondance de biens ecclésiastiques appartenant au clergé séculier, en particulier aux chanoines de Saint-André, et la part du bâti possédée par ces derniers était bien supérieure à celle des réguliers dans ce quartier (fig. 8 et tableau 2). Cet espace était donc clairement sous l'emprise de l'Église mais les réguliers, qui prenaient part à cette domination spatiale, n'en constituaient pas les principaux bénéficiaires. Les possessions du chapitre de Saint-Seurin se concentraient dans leur propre faubourg, correspondant au territoire du régiment de Saint-Maixant hors la ville.

À l'échelle de la ville, si l'on considère les biens des hôpitaux, des bénéficiers et des fabriques, de grandes propriétés se dessinent. Elles étaient toutefois très dispersées, héritages des décennies passées, de l'accumulation de legs singuliers et disparates - les mieux dotés étant l'hôpital Saint-André, l'hôpital de la Manufacture, et les bénéficiers de Saint-Michel. Ces autres institutions apparaissaient comme les détenteurs majoritaires du patrimoine foncier de l'Église dans les régiments Saint-Michel et Saint-Pierre.

En somme, le clergé exerçait un poids assez lourd sur le foncier, à Bordeaux, comme dans la plupart des villes épiscopales ${ }^{72}$. Pour approfondir encore cette réflexion, il faudrait construire des comparaisons de même échelle. Il serait judicieux de comparer l'ensemble des possessions de l'Église avec l'ensemble des possessions de la noblesse, et par voie de conséquence, les propriétés des religieux avec celles des parlementaires, ou bien encore le temporel d'une communauté religieuse avec celui

\footnotetext{
${ }^{70}$ Philippe Loupès, Chapitres et chanoines de Guyenne aux XVII et XVIII siècles, Paris, EHESS, 1985, p. 89-112 et p. 146-148. Cependant, Philippe Loupès a cherché à ramener la puissance temporelle des grands chapitres de Guyenne à de justes proportions en montrant que la trentaine de maisons que possédait chacun des deux chapitres bordelais soutenait difficilement la comparaison avec les 121 immeubles du chapitre métropolitain de Reims dans la ville, et les 173 maisons du chapitre cathédral de Chartres tant à la ville qu'à la campagne. En cumulant les fiefs urbains, les dîmes et les ressources bénéficiales, ils n'en demeuraient pas moins des entités économiques puissantes à l'échelon local. D'après notre étude du dénombrement des maisons et échoppes à Bordeaux au milieu du XVIII ${ }^{\mathrm{e}}$ siècle, 159 biens immobiliers leur appartenaient mais cette donnée englobe les propriétés des chapitres, les maisons canoniales et les habitations possédées par des prébendiers ou des chanoines, parfois occupées par eux (18 cas) mais plus souvent mises en location.

${ }^{71}$ Ibid., p. 95-96.

${ }^{72}$ D. Dinet, Religion et société, op. cit., t. 1, p. 270.
} 
Pour citer cet article : LORIAUD Aude, « De vastes propriétés au cour des villes : le patrimoine urbain des communautés régulières à Bordeaux au milieu du XVIII ${ }^{\mathrm{e}}$ siècle $"$, Histoire, économie \& société, n²/2019 : L'emprise foncière des religieux dans l'espace urbain sous l'Ancien Régime, juin 2019, p. 23-46.

d'une seule famille. Une piste possible consisterait à construire une grille d'analyse pour apprécier à sa juste valeur l'ampleur du patrimoine foncier des différents groupes sociaux.

Les grands enclos conventuels cernés de hauts murs et les vastes propriétés aux mains des réguliers représentaient une forte emprise foncière au cœur de la ville, inscrivant de manière visible leur puissance dans le paysage urbain, à Bordeaux comme dans d'autres villes, grandes ou moyennes, au $\mathrm{XVII}^{\mathrm{e}}$ et au XVIII ${ }^{\mathrm{e}}$ siècle. Sans avoir conscience de l'emprise foncière que représentaient toutes les propriétés urbaines ecclésiastiques cumulées, les réguliers envisageaient la ville comme un espace d'opportunités où ils réalisaient des investissements locatifs dont les recettes permettaient de répondre à leurs propres besoins matériels. Néanmoins, les conflits liés aux biens immobiliers, le plus souvent des procédures pour loyers impayés ou sur des maisons hypothéquées, généraient de manière récurrente des procédures judiciaires accaparantes et coûteuses, ce qui incite à relativiser encore un peu plus la richesse que les communautés religieuses pouvaient tirer de leur patrimoine urbain. 
Pour citer cet article : LORIAUD Aude, « De vastes propriétés au cour des villes : le patrimoine urbain des communautés régulières à Bordeaux au milieu du XVIII ${ }^{\mathrm{e}}$ siècle ", Histoire, économie \& société, $\mathrm{n}^{\circ} 2 / 2019$ : L'emprise foncière des religieux dans l'espace urbain sous l'Ancien Régime, juin 2019, p. 23-46.

Tab. 1 - Typologie des propriétés urbaines des réguliers bordelais au milieu du $\mathrm{XVIII}^{\mathrm{e}}$ siècle.

\begin{tabular}{|c|c|c|c|c|c|c|c|}
\hline $\begin{array}{l}\text { Siècle } \\
\text { de la } \\
\text { fonda- } \\
\text { tion }\end{array}$ & Genre & Communautés & $\begin{array}{c}\text { Propriété } \\
\text { fortement } \\
\text { concentrée } \\
\text { (concentration } \\
\text { autour du } \\
\text { couvent ou } \\
\text { dans un seul } \\
\text { quartier) }\end{array}$ & $\begin{array}{c}\text { Propriété } \\
\text { concentrée } \\
\text { (au moins } \\
80 \% \text { des } \\
\text { biens) avec } \\
\text { dispersion sur } \\
\text { deux ou trois } \\
\text { quartiers }\end{array}$ & $\begin{array}{l}\text { Propriété } \\
\text { dispersée } \\
\text { (sur deux } \\
\text { quartiers) }\end{array}$ & $\begin{array}{l}\text { Propriété } \\
\text { largement } \\
\text { dispersée } \\
\text { (sur au } \\
\text { moins trois } \\
\text { quartiers) }\end{array}$ & $\begin{array}{l}\text { Nombre } \\
\text { de biens }\end{array}$ \\
\hline 17 & Femmes & Bénédictines & & & & $\mathrm{x}$ & 51 \\
\hline 16 & Hommes & Jésuites & & & & $x$ & 40 \\
\hline 16 & Femmes & $\begin{array}{l}\text { Religieuses de } \\
\text { l'Annonciade }\end{array}$ & & $x$ & & & 40 \\
\hline 13 & Hommes & Grands Carmes & & $x$ & & & 36 \\
\hline 17 & Femmes & $\begin{array}{l}\text { Carmélites de } \\
\text { l'Assomption } \\
\text { (Petites Carmélites) }\end{array}$ & $x$ & & & & 36 \\
\hline 7 & Hommes & Bénédictins & $x$ & & & & 31 \\
\hline 17 & Hommes & Minimes & $x$ & & & & 21 \\
\hline 17 & Hommes & $\begin{array}{l}\text { Carmes déchaux } \\
\text { (Petits Carmes) }\end{array}$ & & & $x$ & & 17 \\
\hline 17 & Femmes & $\begin{array}{l}\text { Carmélites de } \\
\text { Saint-Joseph } \\
\text { (Grandes } \\
\text { Carmélites) }\end{array}$ & & & & $x$ & 14 \\
\hline 18 & Hommes & $\begin{array}{l}\text { Carmes déchaux } \\
\text { des Chartrons }\end{array}$ & $x$ & & & & 14 \\
\hline 17 & Femmes & $\begin{array}{l}\text { Religieuses de } \\
\text { Notre-Dame }\end{array}$ & & $x$ & & & 13 \\
\hline 16 & Hommes & Feuillants & $x$ & & & & 12 \\
\hline 13 & Hommes & Dominicains & & $x$ & & & 11 \\
\hline 13 & Hommes & Augustins & $x$ & & & & 10 \\
\hline 17 & Femmes & $\begin{array}{l}\text { Filles de la Foi } \\
\text { (Minimettes) }\end{array}$ & $x$ & & & & 8 \\
\hline 17 & Femmes & $\begin{array}{l}\text { Dominicaines de } \\
\text { Sainte-Catherine }\end{array}$ & & & $x$ & & 5 \\
\hline 17 & Femmes & $\begin{array}{l}\text { Filles Orphelines de } \\
\text { Saint-Joseph }\end{array}$ & & $x$ & & & 5 \\
\hline 17 & Femmes & Ursulines & & $x$ & & & 5 \\
\hline 17 & Femmes & Visitation & & & $x$ & & 5 \\
\hline 17 & Femmes & $\begin{array}{l}\text { Religieuses de La } \\
\text { Magdelaine }\end{array}$ & $x$ & & & & 4 \\
\hline 17 & Hommes & Chartreux & & & $x$ & & 2 \\
\hline 14 & Hommes & La Mercy & $x$ & & & & 1 \\
\hline 17 & Hommes & Capucins & $x$ & & & & 1 \\
\hline
\end{tabular}

NB: On entend par «quartier » l'espace contrôlé par un régiment selon les délimitations du dénombrement de la population de Bordeaux vers 1750-1752 (AD, C 1276). 
Fig. 1 - L'emprise foncière des réguliers à Bordeaux : les enclos conventuels vers 1750.

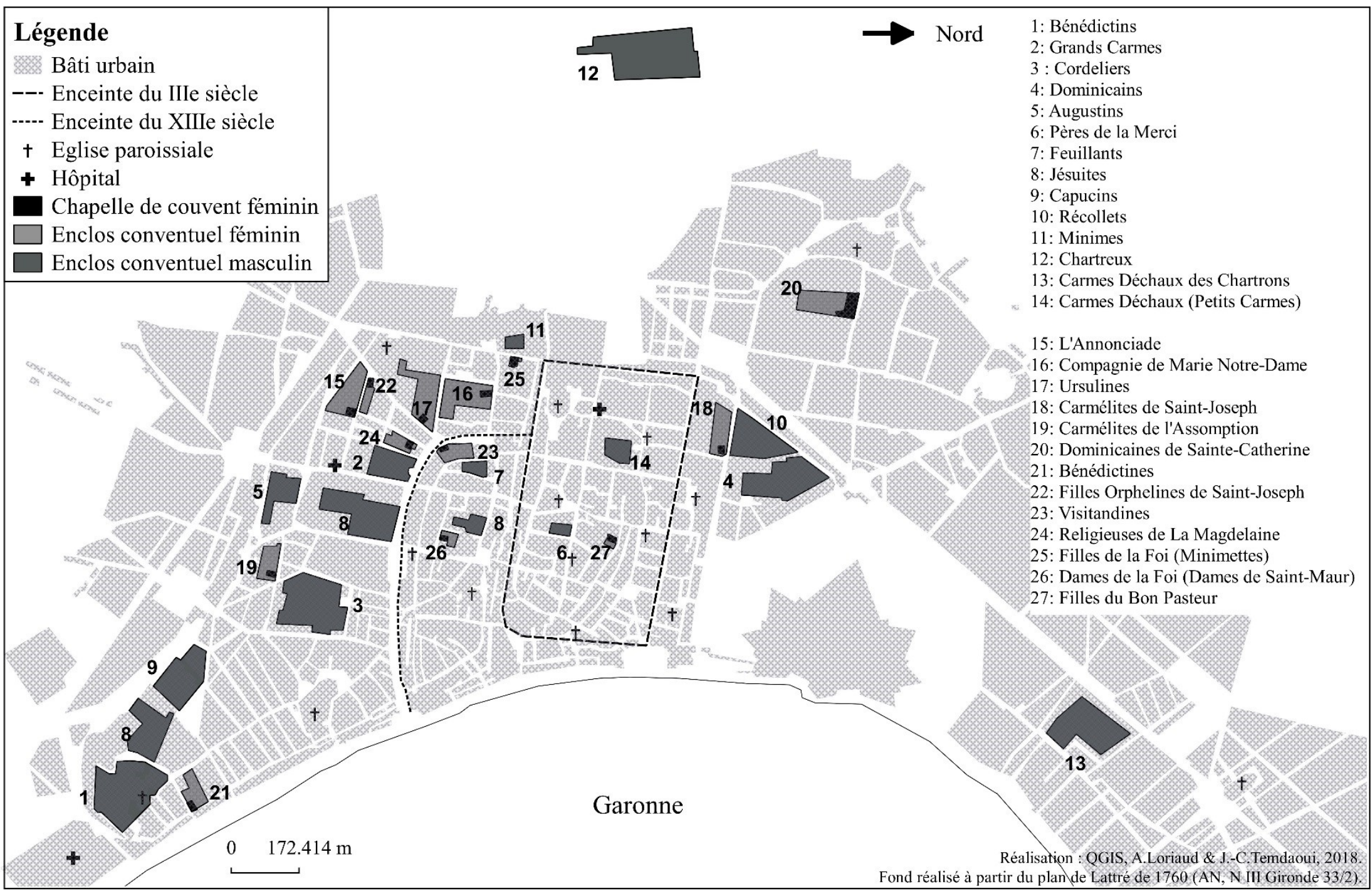




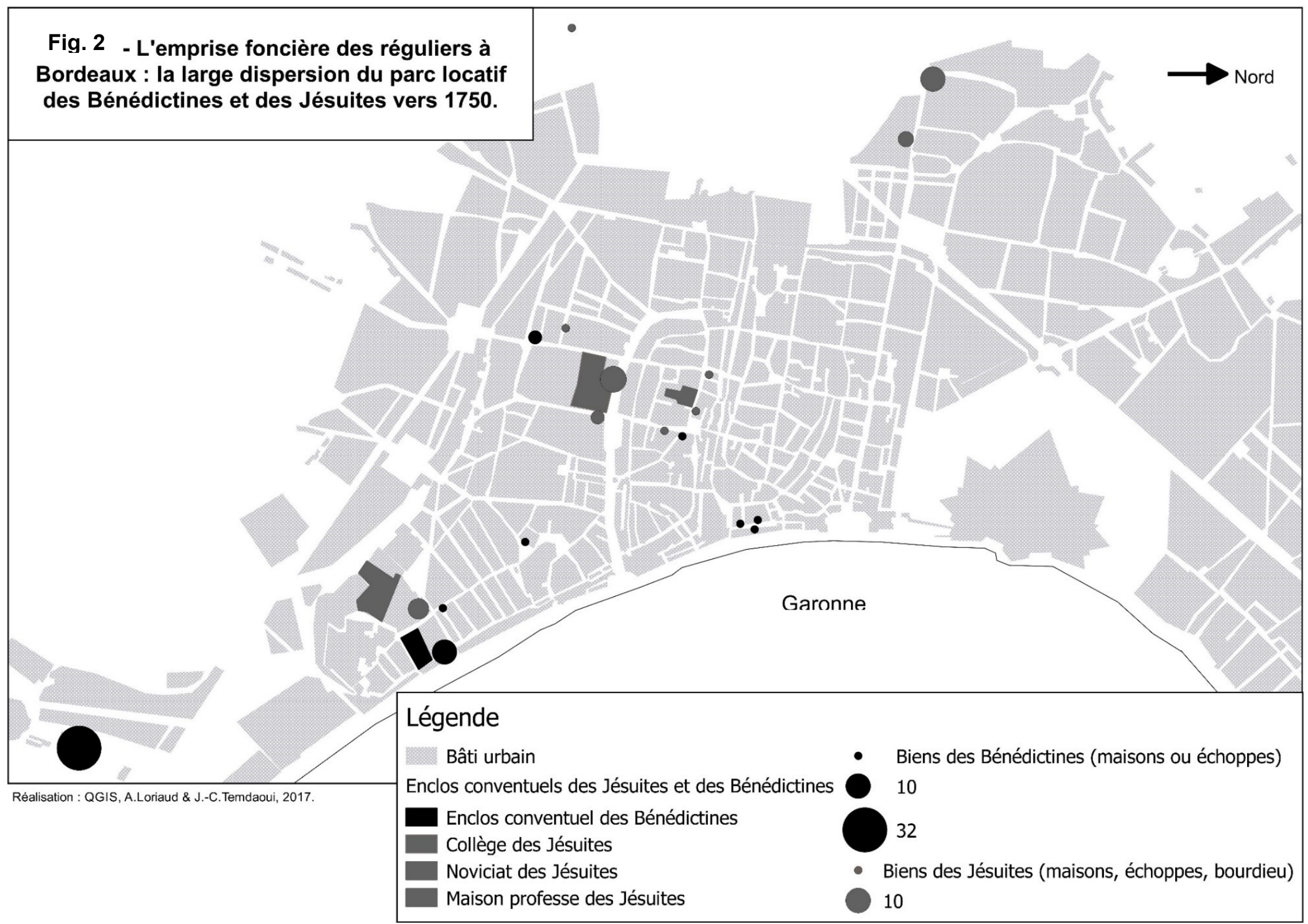


Pour citer cet article : LORIAUD Aude, « De vastes propriétés au cour des villes : le patrimoine urbain des communautés régulières à Bordeaux au milieu du XVIII ${ }^{\mathrm{e}}$ siècle ", Histoire, économie \& société, $\mathrm{n}^{\circ} 2 / 2019$ : L'emprise foncière des religieux dans l'espace urbain sous l'Ancien Régime, juin 2019, p. 23-46.

Fig. 3 - Part des propriétés immobilières des réguliers (hors bâtiments conventuels) dans chaque quartier régimentaire de Bordeaux vers 1750 .

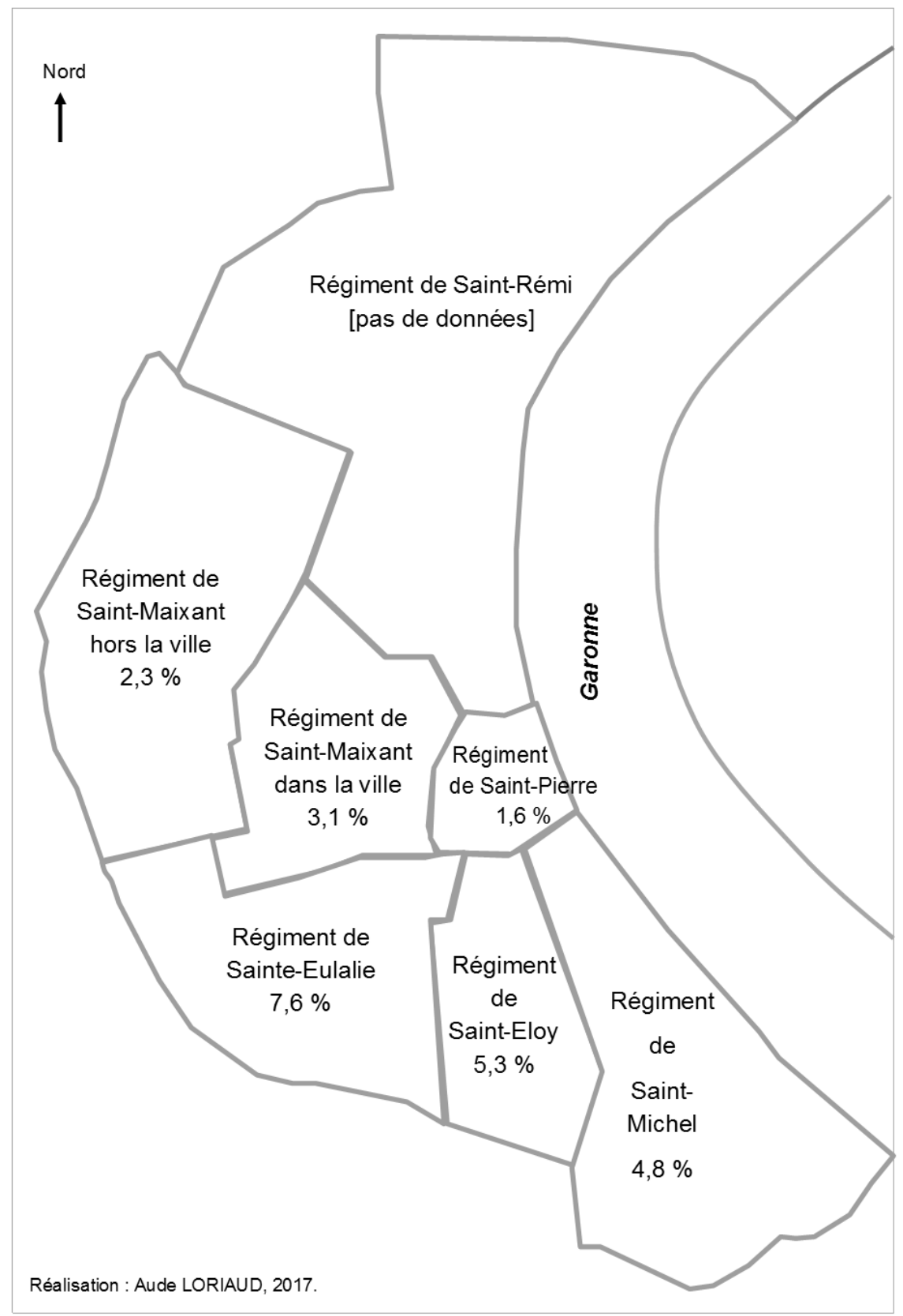


Pour citer cet article : LORIAUD Aude, « De vastes propriétés au cour des villes : le patrimoine urbain des communautés régulières à Bordeaux au milieu du XVIII ${ }^{\mathrm{e}}$ siècle ", Histoire, économie \& société, $\mathrm{n}^{\circ} 2 / 2019$ : L'emprise foncière des religieux dans l'espace urbain sous l'Ancien Régime, juin 2019, p. 23-46.

Tab. 2 - Tableau comparatif des propriétés urbaines ecclésiastiques à Bordeaux au milieu du XVIII ${ }^{\mathrm{e}}$ siècle.

\begin{tabular}{|c|c|c|c|c|c|c|c|}
\hline & $\begin{array}{c}\text { Maisons et } \\
\text { échoppes } \\
\text { apparte- } \\
\text { nant aux } \\
\text { commu- } \\
\text { nautés de } \\
\text { reli- } \\
\text { gieuses }\end{array}$ & $\begin{array}{l}\text { Maisons } \\
\text { et } \\
\text { échoppes } \\
\text { apparte- } \\
\text { nant aux } \\
\text { commu- } \\
\text { nautés de } \\
\text { religieux }\end{array}$ & 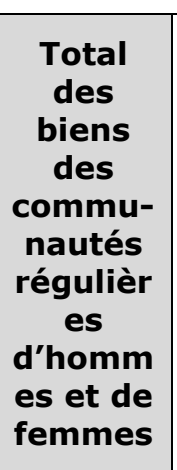 & $\begin{array}{c}\text { Maisons } \\
\text { appartenan } \\
\text { t aux } \\
\text { chapitres } \\
\text { Saint- } \\
\text { André et } \\
\text { Saint- } \\
\text { Seurin ou } \\
\text { aux } \\
\text { chanoines }\end{array}$ & $\begin{array}{c}\text { Autres } \\
\text { biens } \\
\text { ecclésias- } \\
\text { tiques } \\
\text { (détenus } \\
\text { par le } \\
\text { clergé } \\
\text { séculier, } \\
\text { les } \\
\text { paroisses } \\
\text { et les } \\
\text { hôpitaux). }\end{array}$ & $\begin{array}{c}\text { Total } \\
\text { des } \\
\text { biens de } \\
\text { l'Église }\end{array}$ & $\begin{array}{c}\text { Total des } \\
\text { maisons } \\
\text { et } \\
\text { échoppes } \\
\text { du régi- } \\
\text { ment }\end{array}$ \\
\hline $\begin{array}{l}\text { Régiment } \\
\text { de Sainte- } \\
\text { Eulalie }\end{array}$ & 77 & 92 & 169 & 0 & 38 & 207 & 2215 \\
\hline $\begin{array}{l}\text { Régiment } \\
\text { de Saint- } \\
\text { Eloy }\end{array}$ & 44 & 16 & 60 & 0 & 41 & 101 & 1140 \\
\hline $\begin{array}{l}\text { Régiment } \\
\text { de Saint- } \\
\text { Maixant } \\
\text { dans la ville }\end{array}$ & 13 & 12 & 25 & 104 & 46 & 175 & 818 \\
\hline $\begin{array}{l}\text { Régiment } \\
\text { de Saint- } \\
\text { Maixant } \\
\text { hors la ville } \\
\text { (faubourg } \\
\text { Saint- } \\
\text { Seurin) }\end{array}$ & 4 & 32 & 36 & 54 & 31 & 121 & 1553 \\
\hline $\begin{array}{l}\text { Régiment } \\
\text { de Saint- } \\
\text { Michel }\end{array}$ & 46 & 33 & 79 & 1 & 116 & 196 & 1652 \\
\hline $\begin{array}{l}\text { Régiment } \\
\text { de Saint- } \\
\text { Pierre }\end{array}$ & 8 & 2 & 10 & 0 & 30 & 40 & 618 \\
\hline $\begin{array}{l}\text { Régiment } \\
\text { de Saint- } \\
\text { Rémy } \\
\text { (paroisse } \\
\text { Saint-Rémy } \\
\text { en ville et } \\
\text { faubourg } \\
\text { des } \\
\text { Chartrons) } \\
\end{array}$ & NR & NR & NR & NR & NR & NR & NR \\
\hline Totaux & 192 & 187 & 379 & 159 & 302 & 840 & 7996 \\
\hline
\end{tabular}


Fig. 4 - Les biens immeubles des communautés régulières dans la ville de Bordeaux et ses faubourgs au milieu du XVIII siècle.

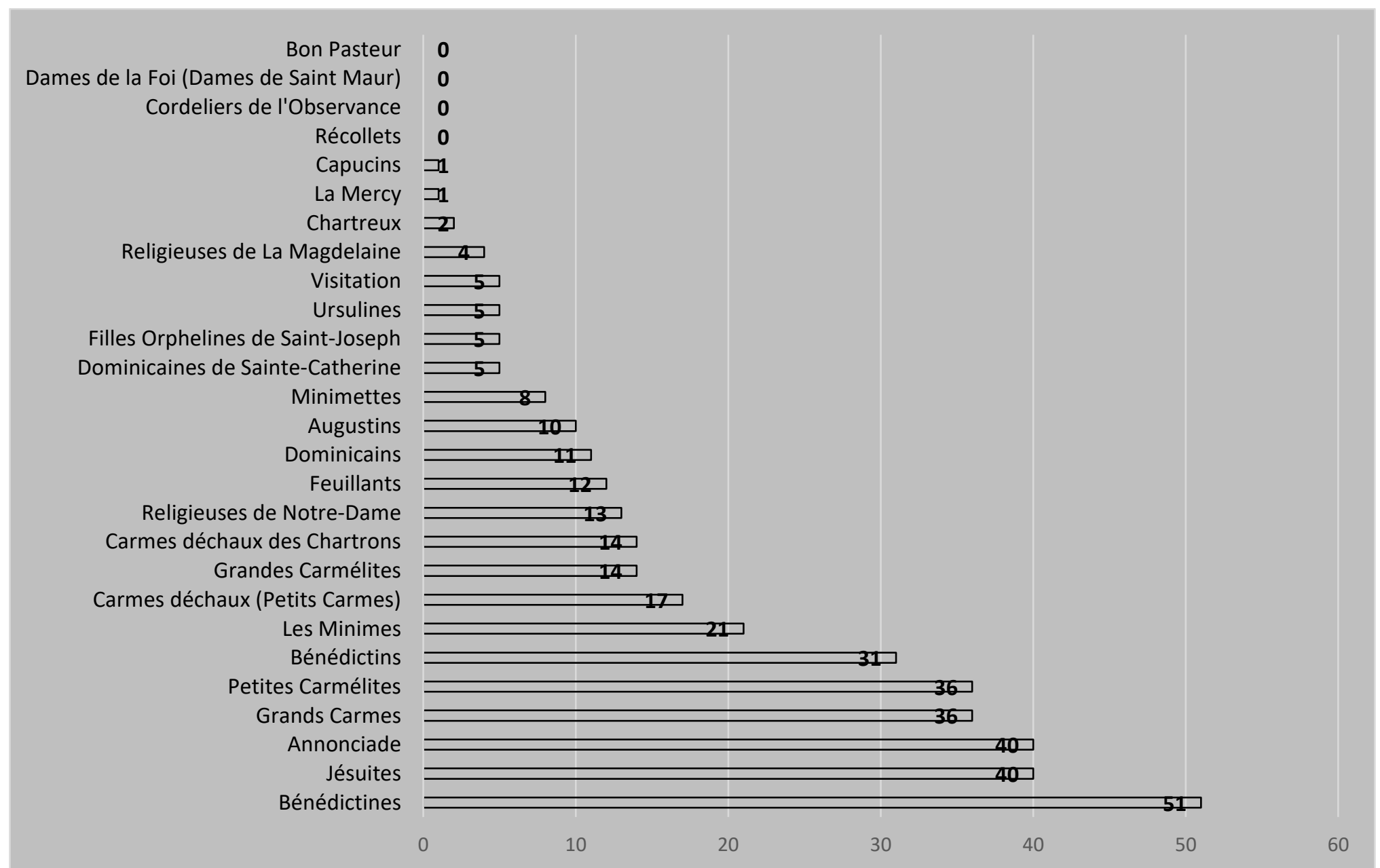

NB : Le dénombrement de 1750-1752 ne fournissant pas de renseignement sur la paroisse Saint-Rémy et le faubourg des Chartrons, nous avons ajouté les 14 maisons indiquées dans la déclaration de revenus des Carmes déchaux des Chartrons de 1760, laquelle a été transcrite par É. Suire dans Les finances des religieux bordelais, op.cit., t. 2, p. 55. 
Pour citer cet article : LORIAUD Aude, «De vastes propriétés au cour des villes : le patrimoine urbain des communautés régulières à Bordeaux au milieu du XVIII siècle ", Histoire, économie \& société, n²/2019: L'emprise foncière des religieux dans l'espace urbain sous l'Ancien Régime, juin 2019 , p. $23-46$.

Fig. 5 - Taux de concentration foncière des biens locatifs des communautés religieuses bordelaises (vers 1750).

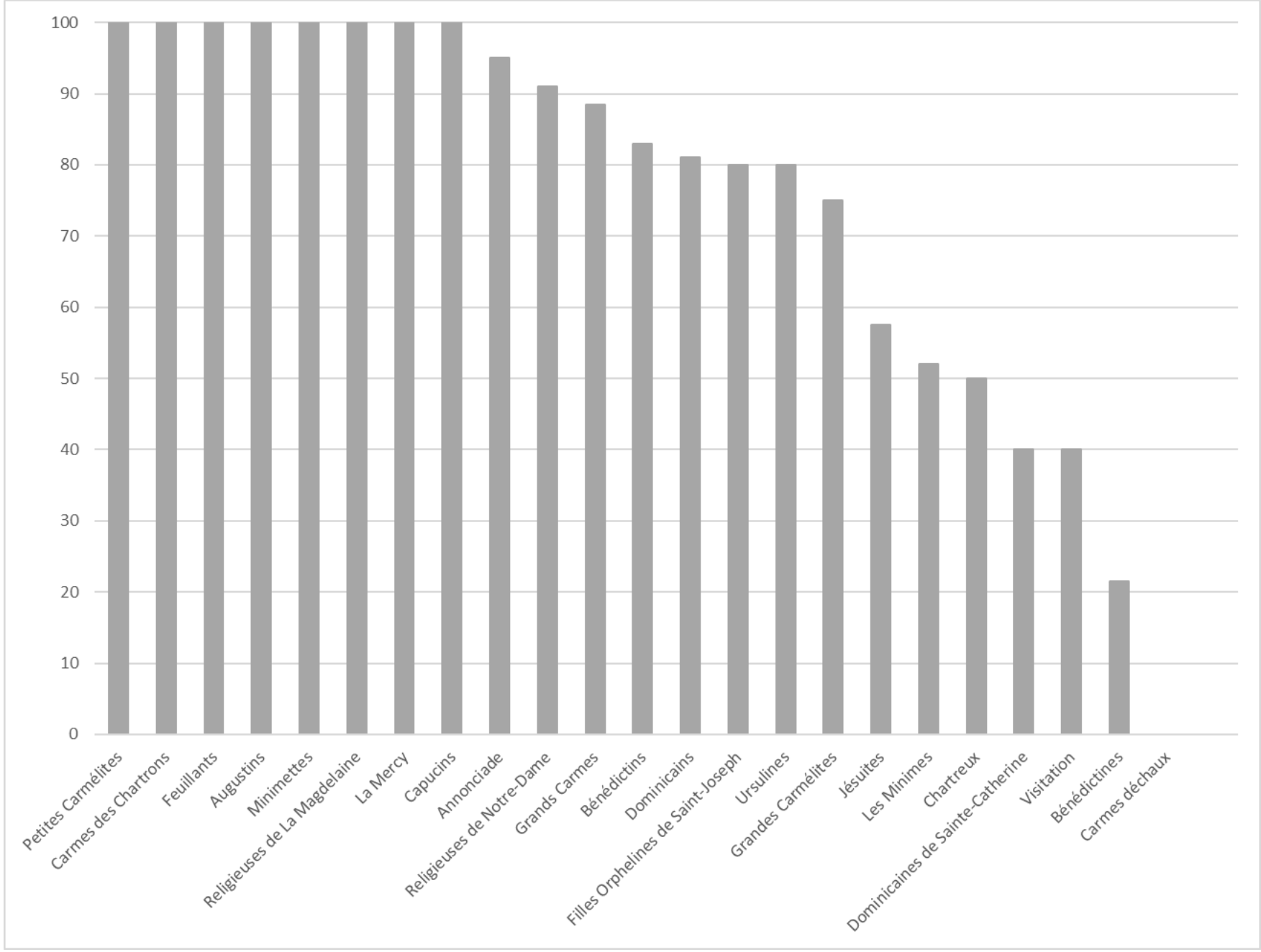

NB : Le taux de concentration est nul pour les Carmes déchaux (Petits Carmes) car tous leurs biens se situaient en périphérie de la ville, loin de leur monastère. 
Pour citer cet article : LORIAUD Aude, « De vastes propriétés au cour des villes : le patrimoine urbain des communautés régulières à Bordeaux au milieu du XVIII ${ }^{\mathrm{e}}$ siècle ", Histoire, économie \& société, $\mathrm{n}^{\circ} 2 / 2019$ : L'emprise foncière des religieux dans l'espace urbain sous l'Ancien Régime, juin 2019, p. 23-46.

Fig. 6 - Part en pourcentage des échoppes dans le parc immobilier urbain des communautés régulières à Bordeaux vers 1750 .

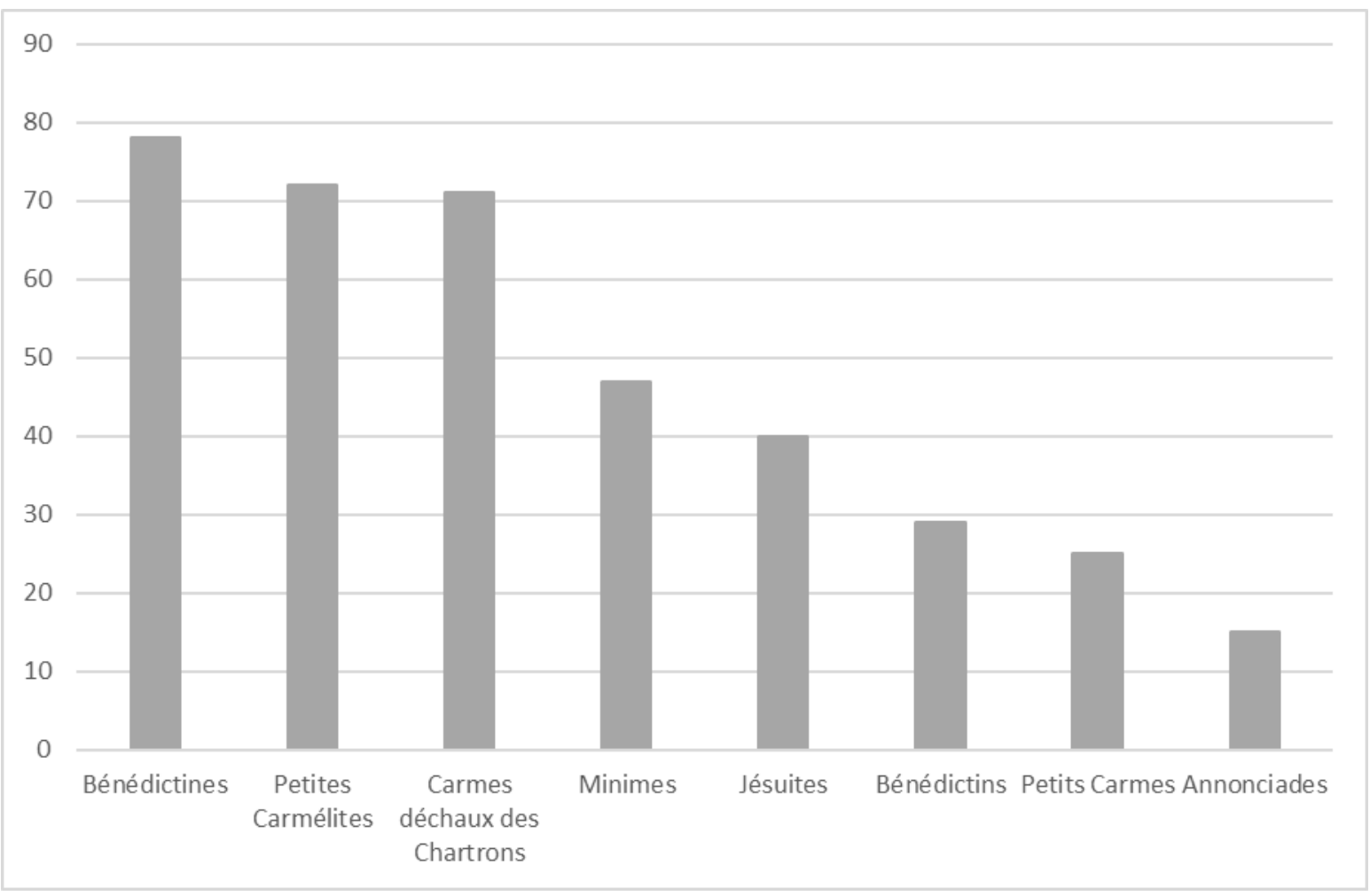


Pour citer cet article : LORIAUD Aude, « De vastes propriétés au cour des villes : le patrimoine urbain des communautés régulières à Bordeaux au milieu du XVIII ${ }^{\mathrm{e}}$ siècle $»$, Histoire, économie \& société, $\mathrm{n}^{\circ} 2 / 2019$ : L'emprise foncière des religieux dans l'espace urbain sous l'Ancien Régime, juin 2019, p. 23-46.

Fig. 7 - Proportion en pourcentage des biens immobiliers des communautés régulières sur l'ensemble du bâti de chaque quartier régimentaire de Bordeaux au milieu du XVIII ${ }^{\mathrm{e}}$ siècle.

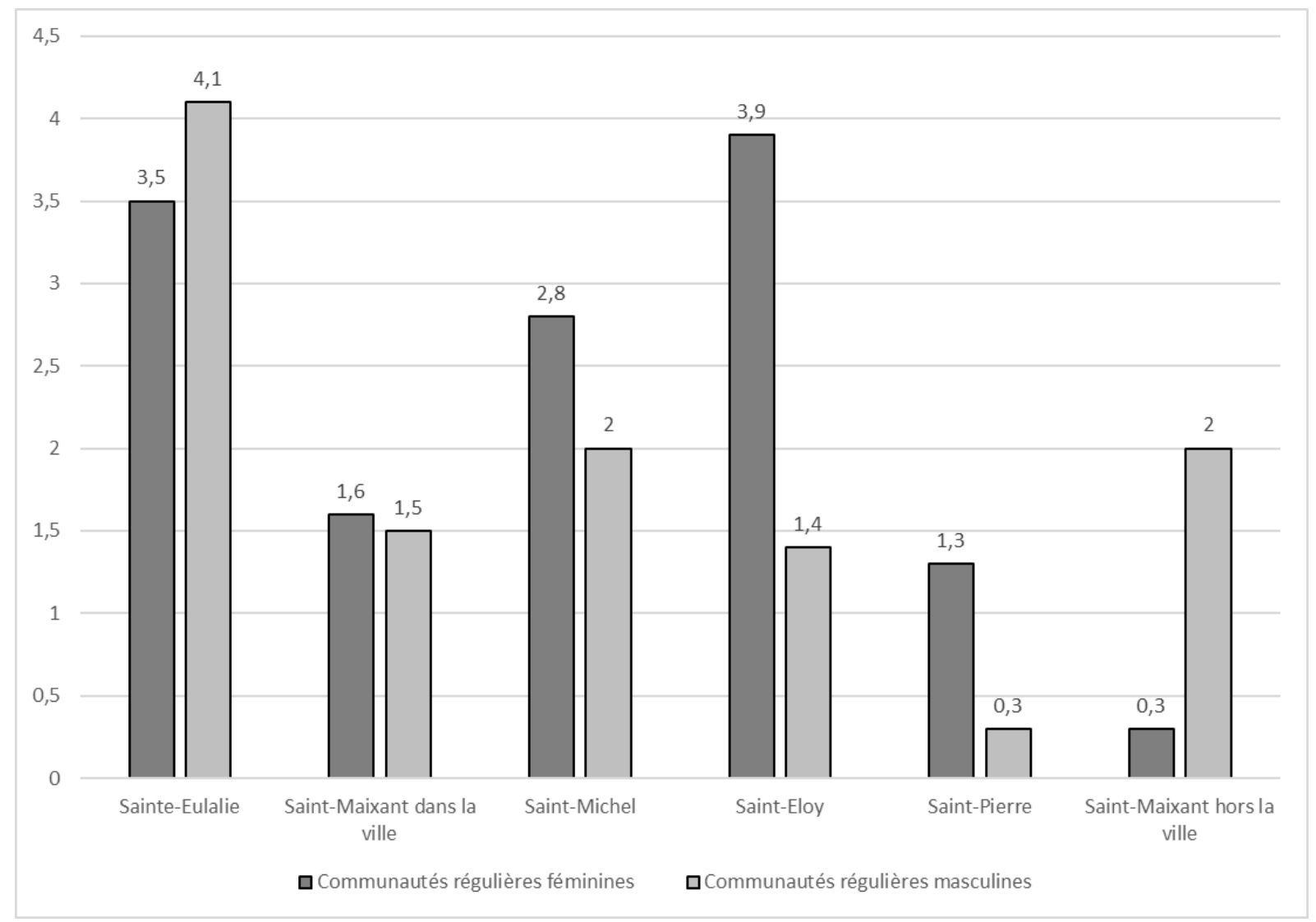


Fig. 8 - La part en pourcentage des biens immobiliers dans le bâti urbain : un indicateur de l'emprise foncière de l'Église à Bordeaux au milieu du XVIII ${ }^{\mathrm{e}}$ siècle.

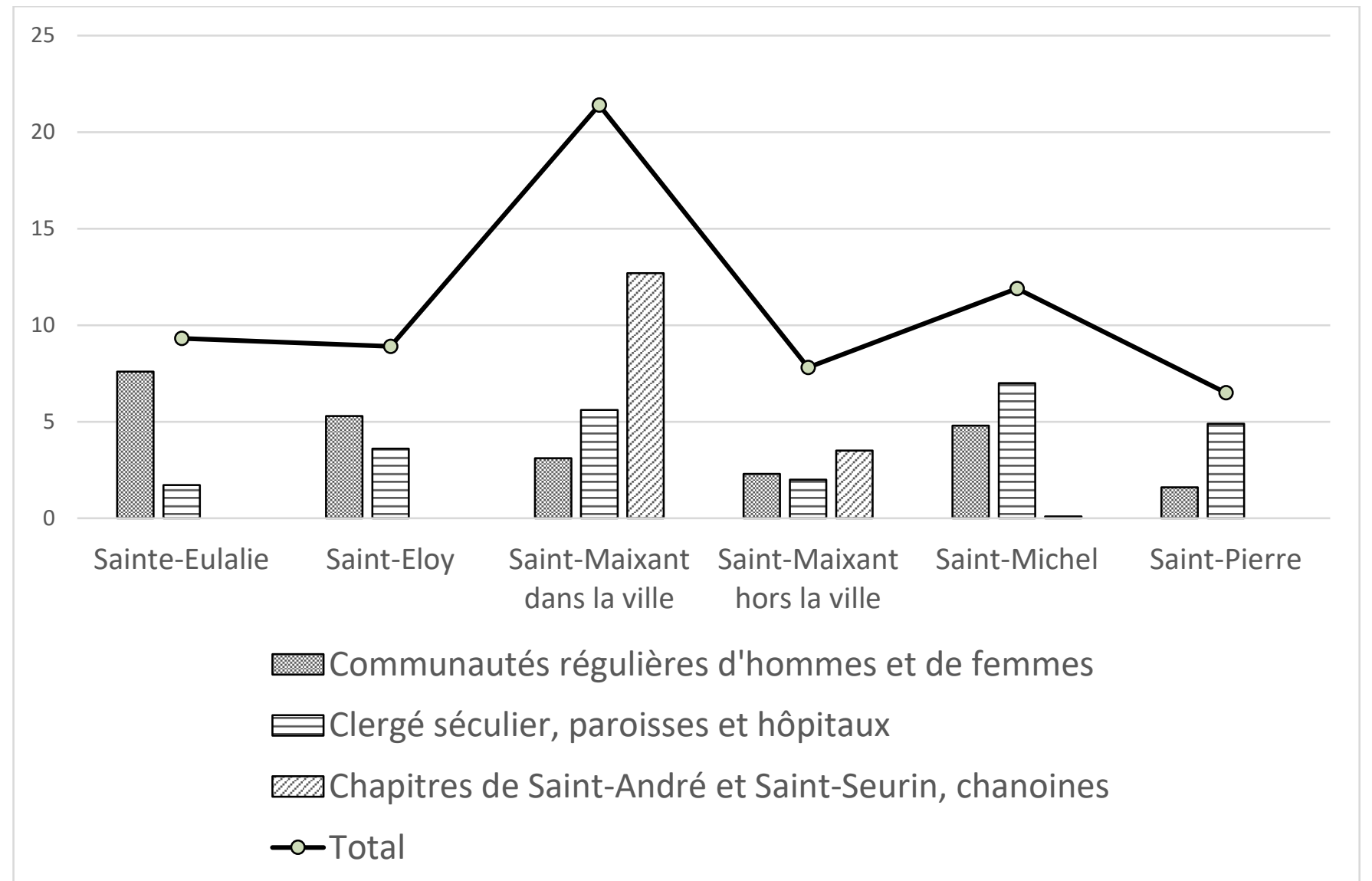

NB : Sous le terme de «paroisses », nous désignons ici les possessions des bénéficiers, des fabriques et « œuvres » des églises, des biens dédiés aux pauvres de la paroisse. 